\title{
Nouveaux apports sur l'archéologie du littoral de Guyane : de la préhistoire à la conquête
}

New data on the archaeology of the French Guiana coastal plains: from prehistory to the Encounter

Novas contribuições para a arqueologia das planícies costeiras da Guiana

Francesa: da pré-história até o Período Cerâmico tardio

\section{Martijn M. van den Bel}

\section{(2) OpenEdition}

\section{Journals}

Édition électronique

URL : https://journals.openedition.org/jsa/16464

DOI : 10.4000/jsa.16464

ISSN : $1957-7842$

\section{Éditeur}

Société des américanistes

Édition imprimée

Date de publication : 15 décembre 2018

Pagination : 105-152

ISSN : 0037-9174

Référence électronique

Martijn M. van den Bel, « Nouveaux apports sur l'archéologie du littoral de Guyane : de la préhistoire à la conquête », Journal de la Société des américanistes [En ligne], 104-2 | 2018, mis en ligne le 15 décembre 2018, consulté le 03 septembre 2022. URL : http://journals.openedition.org/jsa/16464 ; DOI : https://doi.org/10.4000/jsa. 16464 


\title{
Nouveaux apports sur l'archéologie du littoral de Guyane : de la préhistoire à la conquête
}

\author{
Martijn M. van DEN BEL *
}

\begin{abstract}
En Guyane française, les recherches archéologiques structurées ne datent que du début des années 1970. Elles furent synthétisées par Stéphen Rostain au début des années 1990. Le cadre chrono-culturel établi alors se concentrait surtout sur la bande littorale entre les rivières de Kourou et de l'Oyapock et sur la période entre 900 et 1700 de notre ère. Cette étude résume les résultats de six fouilles archéologiques préventives plus récentes. Celles-ci permettent d'abord d'étoffer le cadre chrono-culturel de la préhistoire de ce département français. En effet des données nouvelles élargissent substantiellement ce cadre sur l'Âge archaïque et sur la période céramique ancienne, deux époques inconnues jusque-là. De nouveaux éléments renouvellent aussi certaines perspectives de la période céramique récente, en particulier sur les pratiques funéraires, les complexes céramiques et l'alimentation des Amérindiens. [Mots-clés: Guyane, archéologie, préhistoire, Âge archaïque, Âge céramique ancien, Âge céramique tardif.]
\end{abstract}

New data on the archaeology of the French Guiana coastal plains: from prehistory to the Encounter. In French Guiana, structured archaeological research only started in the early 1970s. Its results have been synthesized by Stéphen Rostain twenty year later. The proposed chronocultural framework focused mainly on the coastal plains situated between the Oyapock and Kourou Rivers for the Late Ceramic Age, between AD 900 and 1700. This study presents the condensed results of six recent compliance archaeological excavations. They permit us firstly to enrich the existing framework of this overseas French department by presenting new data concerning the Archaic and Early Ceramic Ages, hitherto undiscovered episodes, substantially enlarging this framework. Furthermore, new elements concerning the Late Ceramic Age renew certain aspects, notably concerning funerary practices, ceramic complexes and food consumption of the prehistoric Amerindians. [Key words: French Guiana, archaeology, prehistory, Archaic Age, Early Ceramic Age, Late Ceramic Age.]

Novas contribuições para a arqueologia das planícies costeiras da Guiana Francesa: da pré-história até a Conquista. Na Guiana Francesa, pesquisas arqueológicas estruturadas só começaram no início da década de 1970 e seus resultados foram

* INRAP Cayenne, université de Leiden [martijn.van-den-bel@inrap.fr]. 
sintetizados por Stéphen Rostain no início dos anos 1990. O quadro cronocultural proposto focava principalmente nas planícies costeiras situadas entre os rios Oiapoque e Kourou para o Período Cerâmico tardio, entre 900 e 1700 AD. Este estudo apresenta os resultados condensados de seis escavações de arqueologia preventiva. Eles nos permitem, primeiramente, enriquecer o quadro existente deste departamento ultramarino francês; além disso, são apresentados aqui novos dados sobre os Períodos Cerâmicos arcaico e inicial, episódios até então não descobertos, ampliando substancialmente esse panorama. Finalmente, novos elementos relativos ao Período Cerâmico tardio renovam certos aspectos, notadamente, sobre práticas funerárias, complexos cerâmicos e consumo de alimentos das populações ameríndias pré-históricas. [Palavras-chave: Guiana Francesa, Arqueologia, Pré-história, Período arcaico, Período Cerâmico inicial, Período Cerâmico tardio.]

C'est, semble-t-il, le destin constant de la Guyane, que chaque génération, ignorant ou rejetant systématiquement l'œuvre de la précédente, reprenne indéfiniment les tentatives et butte sur les mêmes obstacles. Jean-Marcel Hurault (1989, p. 65)

Il y a presque 25 ans, Stéphen Rostain constatait que « la préhistoire de la Guyane française était pratiquement inconnue » et que « la problématique d'une recherche archéologique en Guyane était de ce fait évidente » (Rostain 1994a, p. 10). Depuis lors, et même si l'état des connaissances rapporté à l'étendue du département (plus de $80000 \mathrm{~km}^{2}$ ) demeure lacunaire, de nouvelles avancées ont eu lieu, tant au niveau géographique, par exemple dans la région à l'ouest de Kourou, qu'au niveau chronologique, notamment avec la découverte de sites précéramiques (période inconnue encore récemment) lors de recherches archéologiques préventives menées au début des années 2000 (van den Bel et al. 2006 ; Mestre et Delpech 2008).

Le paysage de la recherche archéologique a donc changé depuis 1994 (Rostain 1994b), notamment avec les études effectuées autour du barrage de Petit-Saut, premier projet archéologique de sauvetage entamé à la fin des années 1980 (Vacher, Jérémie et Briand 1998). Après ce projet phare sur la rivière Sinnamary, d'autres fouilles extensives et préventives ont eu lieu dans les années 1990 comme celles du Mont-Matoury à Cayenne, de Favard dans les Montagnes de Kaw et sur la future route RN2 entre Régina et Saint-Georges de l'Oyapock. C'est toutefois au début des années 2000 que commencèrent les premiers diagnostics et les fouilles préventives sous la houlette de l'Inrap. Depuis la mise en place locale de cet institut en 2001, ce sont plusieurs centaines de diagnostics et une dizaine de fouilles archéologiques préventives qui ont été effectuées. Ces travaux, cumulés avec les précédents ainsi que les recherches 
programmées, ont modifié l'état des connaissances tel qu'il avait été dressé au milieu des années 1990.

On présentera ici les résultats de six fouilles archéologiques préventives menées par l'auteur entre 2005 et 2010. Ces travaux sont bien évidemment loin d'être les seuls ; on se réfèrera donc aussi, à titre comparatif, à ceux de plusieurs collègues (voir Annexe I). L'article de Rostain, publié dans ce même journal, servira de point de départ, de façon à illustrer les nouveautés et les changements intervenus depuis 1994 dans le cadre chrono-culturel guyanais. Postérieurement à cette date, sur la base de nouvelles fouilles programmées, Rostain lui-même a apporté plusieurs modifications au cadre chrono-culturel qu'il avait proposé initialement, par exemple à propos du complexe céramique tardif de Barbakoeba (Ouest guyanais). On doit mentionner également les recherches programmées de l'ACR «Préhistoire de la côte occidentale de Guyane » qui s'est déroulée entre 2002 et 2005 (Rostain 2015), ainsi que le projet international « Earthmovers » entre 2006 et 2010, plus ambitieux et destiné à prouver la nature anthropique des champs surélevés et leurs rapports avec la culture arauquinoïde sur la bande littorale occidentale guyanaise (Renard 2010 ; Coutet 2011 [2009]; McKey et al. 2010, 2014 ; Iriarte et al. 2012).

Les sites dont il sera question ici ont été étudiés dans le cadre de l'archéologie préventive française, dont les avantages et les inconvénients font toujours l'objet de débats. Un apport indéniable de celle-ci est assurément l'énorme augmentation des données archéologiques qu'elle a permise. Outre cet aspect quantitatif, on doit aussi souligner la qualité des fouilles de ce type car, autant en contextes périurbains que dans des zones plus ou moins dépeuplées, elles se caractérisent par la mise au jour de surfaces de plusieurs milliers de mètres carrés, ce qui aboutit généralement à l'exposition de centaines d'anomalies à tester avec du mobilier, notamment céramique et lithique. Ce genre de fouilles fournit des données bien supérieures à celles que l'on obtient par des prospections pédestres, des études de collections privées ou des sondages manuels de quelques mètres carrés comme cela se faisait avant les années 1990. Les informations recueillies de cette manière permettent en effet de mieux définir les cadres chrono-culturels des secteurs étudiés (voir Annexe II).

Le cadre chrono-culturel qui sera exposé et discuté ci-dessous s'appuie sur une synthèse de travaux plus anciens et sur des données nouvelles issues des six fouilles préventives déjà mentionnées et qui se sont situées dans la partie occidentale de la Guyane, sur la bande littorale entre l'île de Cayenne et le fleuve Maroni (Figure 1). Ce cadre couvre l'Âge archaïque (9000 à 3000 av. J.-C.), l'Âge céramique ancien (de 3000 av. J.-C. à 900 apr. J.-C.), l'Âge céramique récent/tardif (entre 900 et 1500) et l'Âge moderne ou historique (1500-1950) ${ }^{1}$.

1. La chronologie par Âges (Lithic, Archaic, Ceramic et Historic) - développée depuis les années 1950 par, entre autres, Irving Rouse et Gordon Willey - a fait consensus parmi les 


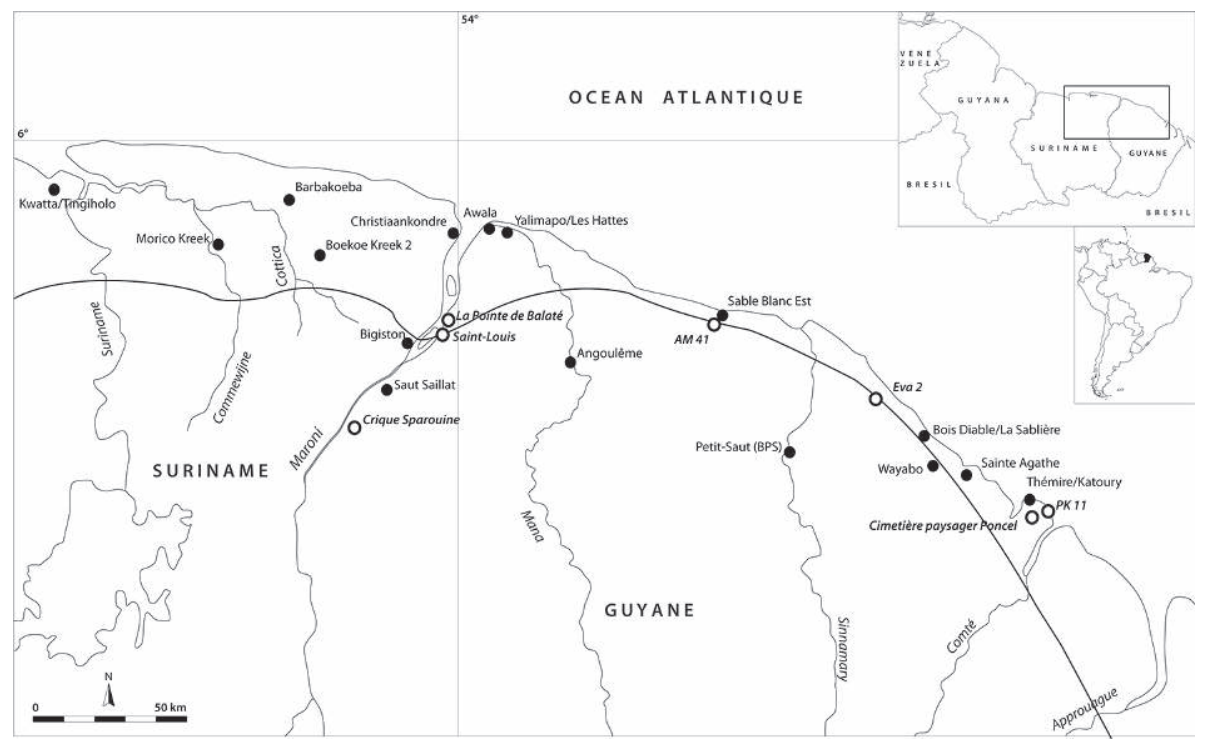

Fig. 1 - Carte de la bande littoral entre les rivières Approuague et Suriname avec les sites archéologiques discutés dans la présentation

(carte par M. van den Bel).

Les recherches récentes ont mis en évidence des vestiges qui attestent, pour la première fois, d'occupations humaines aux deux premiers âges cités. Elles ont apporté aussi des indices qui ouvrent la voie à des modifications et des compléments sur les complexes céramiques Barbakoeba, Koriabo et Thémire. En revanche, aucun vestige remontant à la fin du Pléistocène et attribuable à l'Âge lithique, n'est encore connu en Guyane française ${ }^{2}$.

archéologues travaillant dans les Caraïbes, les Guyanes occidentales et ailleurs à partir des années 1970 pour décrire la culture matérielle (Willey 1971 ; Rouse 1972). Elle remplace une nomenclature (Paleo-Indian, Meso-Indian et Neo-Indian) proposée auparavant par Irving Rouse et José Cruxent (1963), qui suppose une corrélation directe entre la culture matérielle et les modes de subsistance s'avérant intenable pour les Amériques. Malgré cela, cette dernière terminologie demeure toujours populaire aux Antilles et peut s'utiliser finalement aussi pour désigner un mode de vie. Pour la Guyane, l’Âge historique se divise en précolonial (1500-1650), colonial (1664-1848) et contemporain (1848 à nos jours).

2. Cet article est une sorte de résumé en français de la thèse doctorale de l'auteur soutenue à l'université de Leyde, le 3 septembre 2015. Celle-ci avait été dirigée par les professeurs Corinne Hofman et Arie Boomert et elle a été publiée par Sidestone Press (van den Bel 2015b). L'auteur tient à remercier ses directeurs et les membres de son jury pour leurs nombreuses suggestions. Un grand merci également aux équipes de l'Inrap pour leur aide précieuse lors des fouilles et des études post-fouille entre 2005 et 2010. 


\section{L'Âge archaïque tardif}

La carrière dite « Eva » a été exploitée par le Centre spatial guyanais pour la construction du pas de tir de Soyouz (Figure 1). Le site archéologique d'Eva 2 se localise sur le sommet (environ 26 m NGG et 2,5 ha en surface) d'une colline de sables blancs (série détritique de base) qui se trouve à la limite entre le socle précambrien et la plaine côtière pléistocène (formation de Coswine), au sudouest du hameau de Malmanoury dans la commune de Sinnamary (Choubert et al. 1958 , fig. 1$)^{3}$.

À environ $1 \mathrm{~m}$ de profondeur, on a localisé un paléosol (10 à $15 \mathrm{~cm}$ d'épaisseur) contenant les vestiges d'une occupation archaïque, datée par radiocarbone entre 4500 et 2000 av. J.-C. Cette occupation est matérialisée par la présence de grandes quantités de produits de débitage en quartz, par des outils en pierre polie, des amas de blocs de quartz et de la céramique très fragmentée. Ce niveau ancien a été décapé sur une surface d'environ un demi-hectare en collectant le mobilier par unité de $2 \times 3 \mathrm{~m}$. À l'intérieur du sol et immédiatement au-dessous furent dénombrés plus de 200 amas de blocs de quartz répartis en trois zones distinctes. Pour des questions de temps et au vu de la grande quantité de mobilier présent, il a été choisi de procéder à un échantillonnage de cette couche sur une surface de $50 \mathrm{~m}^{2}$, avec tamisage des contenus sur plusieurs niveaux arbitraires (Secteur 12)4. Deux autres sites de cette époque, sur sables blancs, sont apparus en Guyane: celui de Plateau des Mines (PDM), à SaintLaurent-du-Maroni (Mestre et Delpech 2008) et, plus récemment, celui de Luna (Briand 2015), proche d'Eva 2. Ces derniers établissements comportaient aussi une occupation amérindienne attribuée à l'époque historique (van den Bel 2010c ; van den Bel et al. 2015).

\section{Le mobilier lithique}

Le débitage sur enclume ou bipolaire est le mode de production le plus important du site. Ce débitage du quartz produit principalement des éclats et des fragments à l'exception de quelques produits laminaires sur le site de Chemin Saint-Louis à Saint-Laurent-du-Maroni. Les occupants se sont servis de filons de pegmatites qui affleurent à l'ouest et au sud, ainsi que dans les criques environnantes. Ils ont également collecté des blocs de dolérite et d'amphibolite

3. En Guyane, les sables blancs correspondent à des dépôts pliocènes constitués de sédiments blancs très lessivés (moins de $1 \%$ d'argile) et de sédiments brun-jaunâtres non lessivés (5-20 \% d'argile ; de Boer 1972, p. 45). Leur origine géomorphologique et leur pédogenèse font encore l'objet d'un important débat, mais la présence de sites d'occupation pourrait aider les géologues à trancher cette question (Vincent Freycon, CIRAD, comm. pers. 2012).

4. Il faut noter ici que cette occupation archaïque n'avait pas été reconnue lors du diagnostic, ce qui a posé un véritable problème logistique lors de la fouille. 
pour la fabrication de haches pétaloïdes, de pilons et de mortiers. Cependant, l'identification de ces deux dernières matières est extrêmement difficile à l'œil nu et des analyses géochimiques seront nécessaires pour déterminer leurs provenances. On note également l'usage de gneiss, de tufs et d'oxydes de fer.

La grande majorité des outils est constituée d'éclats de quartz ayant une morphologie triangulaire à quadrangulaire et souvent une section trapézoïdale. La plupart mesurent $2 \mathrm{~cm}$ environ, mais certains atteignent entre 2 et $4 \mathrm{~cm}$. Les retouches sont rares: seulement deux (grands) éclats représentent des racloirs. Il s'agit d'un débitage opportuniste destiné à obtenir des éclats de petite taille. Il s'avère difficile de déterminer la fonction de ces éclats : des analyses microscopiques (tracéologie) et de l'expérimentation sont nécessaires pour avancer sur le sujet ${ }^{5}$.

Les nucléus recueillis sont également de petite taille $(<4 \mathrm{~cm})$, car ils sont pratiquement épuisés. Ils sont de formes très variées. Cette diversité s'explique par une trajectoire de taille aléatoire, mais aussi par la réutilisation de plusieurs pièces comme percuteurs.

Douze haches polies ont été trouvées et elles ont de 7 à $20 \mathrm{~cm}$ de longueur, pour une largeur de $6 \mathrm{~cm}$ en moyenne et une épaisseur comprise entre 2 et $4 \mathrm{~cm}$. Elles sont toutes en dolérite ou en amphibolite. Sept haches sont triangulaires, quatre rectangulaires et une trapézoïdale, et elles ont toutes un tranchant lisse. L'une possède un double tranchant. Un spécimen se classe plutôt comme herminette.

Quatorze gros blocs abrasés sur une ou deux faces ont été identifiés comme des meules. Il s'agit de meules en quartz, en granite, en dolérite et en roche indéterminée, dont quatre ont été échantillonnées pour des analyses d'amidon (Figure 2a-b). Les résultats ont démontré la présence de granules d'amidon de maïs, de patates douces, de dictames et de pois sabres. Il s'agit de résultats importants à propos des modes de subsistance des populations de l'Archaïque tardif (Pagán Jiménez et al. 2015).

Enfin, on a dénombré également six molettes, trois pilons, deux broyeurs ou " edge grinders » ayant une face aplatie, un mortier et un calibreur (Figure 2c). Concernant la distribution spatiale du mobilier lithique, deux zones contiennent de nombreux artefacts en pierre, mais plusieurs concentrations d'outils correspondent à des espaces où peu d'amas de blocs de quartz ont été trouvés. On pourrait ainsi distinguer des zones d'activités distinctes: les unes dédiées aux amas de quartz et les autres à la fabrication des outils en pierre.

5. Signalons ici les expérimentations sur le débitage de quartz sur enclume au Brésil d'André Prous (et al. 2010) ou encore celles d'Ignacio Clemente-Conte (Clemente-Conte, Boëda et Faira-Gluchy 2016). L'analyse tracéologique sur des artéfacts en quartz s'avère encore difficile mais des expérimentations ont été faites sur du mobilier en quartz, provenant de Colombie, avec des résultats assez généraux (Nieuwenhuis 2002). 

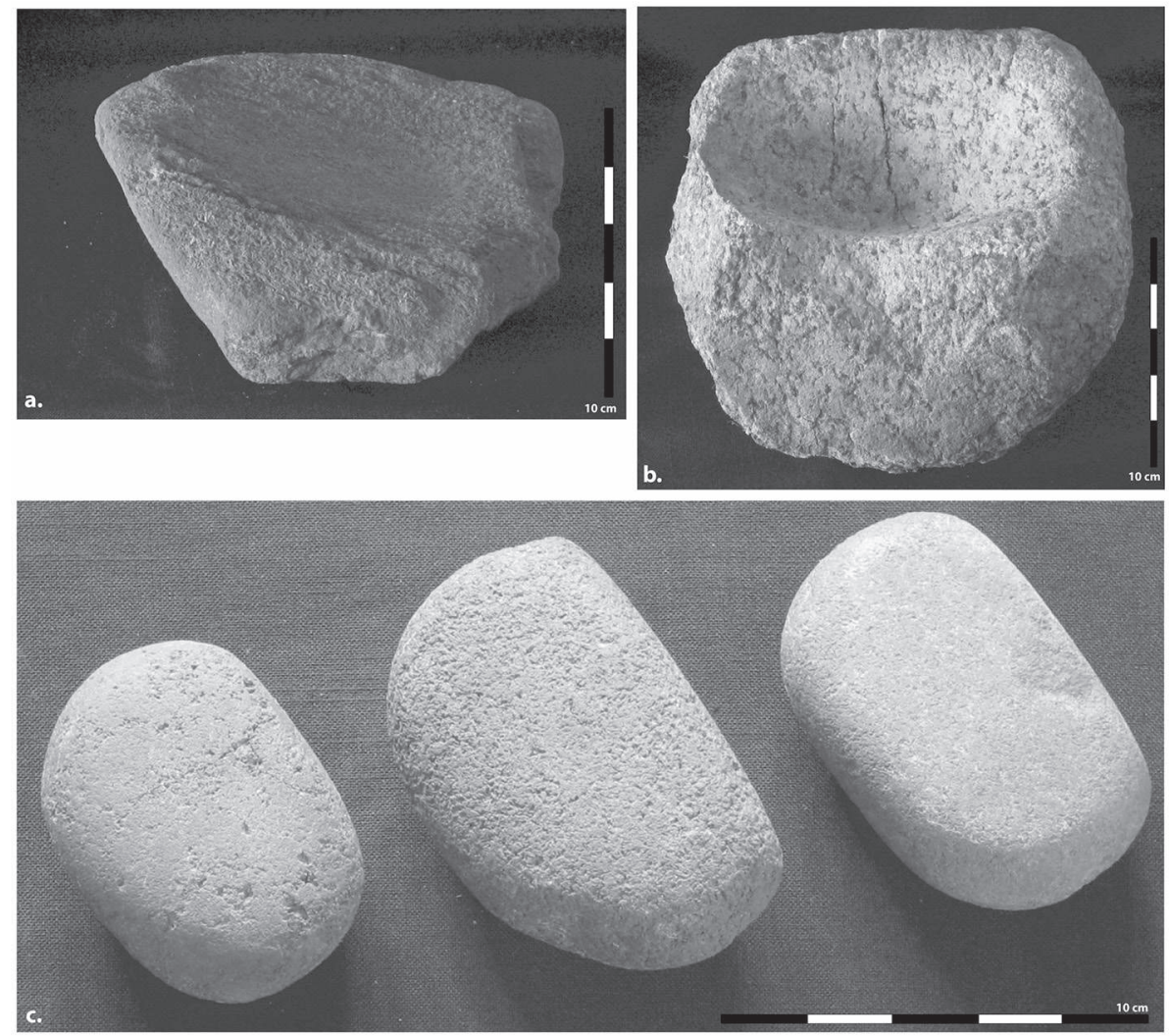

Fig. 2 - Outils à moudre trouvé dans le paléosol du site Eva 2:

a. un meule ; b. un mortier ; c. trois edge grinders (photo par S. Delpech).

\section{Les amas de quartz}

Au total, 210 amas de blocs de quartz ont été identifiés. Ils sont constitués de blocs d'une taille de 5 à $20 \mathrm{~cm}$, souvent organisés dans une petite cuvette d'environ $50 \mathrm{~cm}$ de profondeur (Figure 3a-b). Le tamisage du sédiment provenant des amas a livré de faibles quantités de matières carbonisées (charbons de bois, graines et ossements), mais 58 contenaient des fragments de céramique. Quelques amas se trouvent l'un à côté de l'autre, mais aucun amas ne recoupe un autre. Leur forme est variable et leur taille oscille entre 20 et $120 \mathrm{~cm}$ de diamètre. Certains sont bien organisés, ayant plusieurs couches de blocs superposés, tandis que d'autres sont seulement constitués de quelques blocs dispersés. Au milieu de l'amas se trouve parfois un creux circulaire de 15 à $20 \mathrm{~cm}$ de diamètre (van den Bel 2010b). 
En cours de fouille, on a distingué trois zones avec amas, chacune marquée par une concentration (environ 70 amas par zone). À l'intérieur de chaque zone, on a pu distinguer aussi des ensembles formant des alignements rectilignes ou d'autres organisés en «demi-lune » et constitués de 4 à 6 amas. Au terme de plusieurs interrogations des données sous SIG, il apparaît que la variabilité des dimensions et la diversité des types s'expliqueraient par le fait que les amas ont dû être utilisés plusieurs fois et que la typologie établie renverrait plutôt, soit à des phases d'utilisation, soit à la vidange des cuvettes. On peut donc déduire des amas plusieurs séries de gestes notamment ceux de remplir et de vider les cuvettes de blocs de quartz chauffés. De plus, le fait qu'il n'y ait pas d'amas recoupés montre qu'ils étaient visibles en surface lors de l'occupation du site.

La découverte de ces amas de blocs de quartz et leur distribution spatiale posent évidemment des questions sur leur(s) fonction(s) exacte(s). En Guyane, une seule autre référence existe concernant des amas de blocs de quartz contemporains, celle du PDM : les fouilles ont livré là une dizaine d'amas de quartz comparables avec ceux d'Eva 2 (Mestre et Delpech 2008) ${ }^{6}$. Le fait que les blocs semblent bien organisés et qu'ils aient été chauffés, joint au creusement d'une cuvette peu profonde, évoque un lieu de combustion ou un four. Cependant, ce genre de structure reste inconnu sur le reste du plateau des Guyanes. Pour tenter de trouver des structures identiques, il faudra donc chercher ailleurs ou encore utiliser des analogies ethnographiques. Plusieurs échanges avec des archéologues nord-américains travaillant principalement sur les sites lithiques et archaïques du sud des États-Unis paraissent confirmer l'hypothèse qu'il s'agirait de cuvettes pour pierres chauffantes ou « Fire Cracked Rocks » (Dering 1999 ; Thoms 2003, 2009) (Figure 3c).

\section{La céramique}

Des tessons de céramique montée au colombin, très altérés et fragmentés, ont été trouvés dans le paléosol et parmi les blocs de quartz des amas. Les finitions de surface ainsi que les éventuels décors ont disparu suite au lessivage dans les sables blancs. On a pu isoler 18 éléments constituants (EC) dont 15 bords et 3 bases. Il s'agit de formes ouvertes $(\mathrm{N}=12)$ et fermées $(\mathrm{N}=3)$ dont quatre carénées ayant des diamètres d'ouverture entre 20 et $28 \mathrm{~cm}$ avec lèvre amincie. Les trois bases sont convexes et elles montrent clairement le colombin de départ d'un diamètre d'environ $5 \mathrm{~cm}$. La pâte est constituée d'environ $20 \%$ de sable grossier.

6. Sur le site du Plateau des Mines, les amas étaient constitués de galets et de blocs disposés intentionnellement sur deux épaisseurs et de manière organisée et compacte. Chacun possède également une zone vide de $15 \mathrm{~cm}$ de diamètre pouvant être un négatif de poteau. Toutefois, les blocs provenant des amas ont pu être datés par thermoluminescence, ce qui évoque leur utilisation dans une structure de chauffe ou de combustion (Mestre et Delpech 2008). 
Nouveaux apports sur l'archéologie du littoral de Guyane
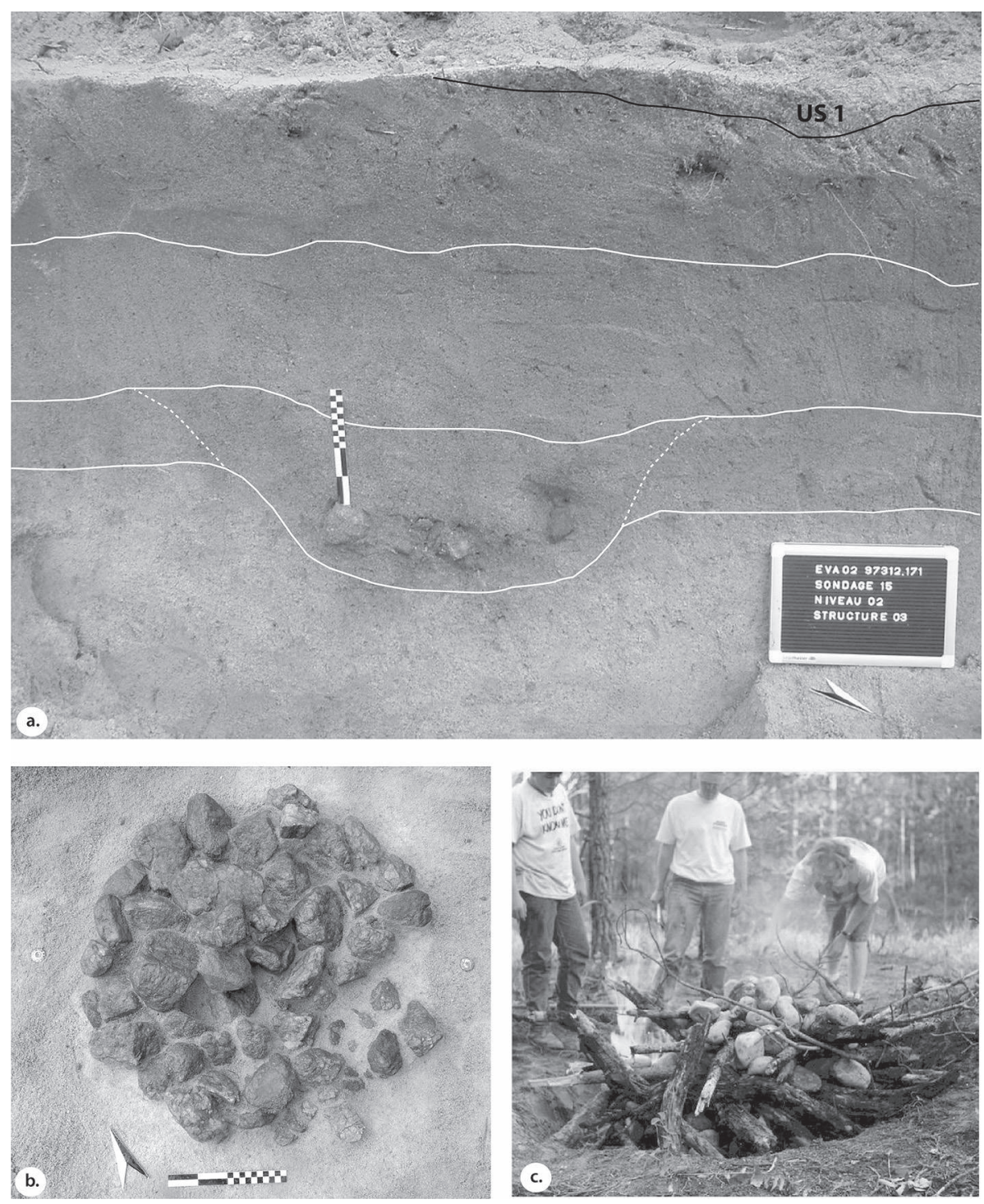

Fig. 3 - Amas de pierres du site Eva 2: a. amas en coupe dans le paléosol (photo par M. van den Bel), b. amas en vue zénithale (photo par M. van den Bel) et c. l'expérimentation d'un four à pierre chauffées (photo par Alston Thoms, avec mes remerciements). 
Martijn M. vAN DEN BEL

\section{Conclusion}

Les fouilles d'Eva 2 et celles du PDM ont révélé un nombre conséquent d'éléments concernant l'occupation archaïque tardive de la plaine littorale de la Guyane.

- La localisation sur les sables blancs montre que les archéologues doivent prêter attention aux paléosols dans cette formation géologique.

- Ces paléosols contiennent de grandes quantités de mobilier lithique, notamment des éclats de moins de $2 \mathrm{~cm}$, issus d'un débitage bipolaire.

- On y trouve également des amas de blocs de quartz dans des cuvettes. Ils s'alignent parfois et forment des concentrations limitées. Il s'agit probablement de fours qui représentent ainsi une activité importante de la préparation d'aliments sur place.

- La présence d'outils à moudre (meules, molettes, pilons) conforte cette hypothèse et représente une autre phase de préparation des aliments. Les analyses des amidons indiquent la présence de maïs, de patates douces et de dictames.

Les dates au radiocarbone, la présence du débitage bipolaire et les outils à moudre font penser aux séries culturelles précéramiques ortoiroïdes telles que définies par Cruxent (1971), par Rouse (1992) et par Boomert (2000) pour l'aire circum-caribéenne. Les broyeurs dits " edge grinders », également trouvés sur Eva 2 et sur PDM, constituent un élément caractéristique de ces séries, selon Boomert " Although the function of the edge grinders at the Ortoiroid sites of Trinidad and South American mainland is not sufficiently known [at that time], these implements should be considered as the type artefacts of the Ortoiroid series » (Boomert 2000, p. 74).

La présence d'une céramique ancienne (à partir de 2200 av. J.-C.) sur Eva 2 évoque le complexe El Conchero tardif (Cruxent 1972, p. 39-40), la Phase Alaka tardive (Evans et Meggers 1960, p. 38-53 ; Williams 2003 ; Roosevelt 1995), ainsi que les complexes anciens de Mina au Brésil (Côrrea et Simões 1971; Simões 1981 ; Roosevelt 1995, p. 117 ; Marques 2009) ou encore la tradition, plus large encore, du littoral sud-américain (Willey 1971, p. 361). Eva 2 se placerait donc dans cette tradition de céramique ancienne qui semble apparaitre sur la bande littorale des Guyanes dès 3000 av. J.-C., bande sur laquelle on peut désormais ajouter la Guyane française.

On remarquera cependant que tous les sites mentionnés ci-dessus comprennent aussi des amas de coquilles, lesquels sont absents sur les sites d'Eva 2 et de PDM. Cela pourrait peut-être s'expliquer par le lessivage des sols, le type de site, l'absence de crustacés dans les estuaires guyanais ou encore par les méthodes de fouille. Néanmoins, une économie de subsistance avec fours et meules et, plus tard, la céramique, éléments présents également lors de la Phase Alaka et à Mina, constituent un cas à part. Plusieurs plantes comestibles auraient ainsi 
été cuites à l'étouffé dans les fours ou " earthovens » avec, ou non, d'autres transformations (épluchage, grattage, écrasement...). Il se serait agi d'obtenir des pâtes ou des boulettes (" tamales ») et, plus tard, des soupes épaisses cuites dans des récipients fermés (van den Bel, Knippenberg et Pagán Jiménez 2018). L'introduction des plaques à cuire (pour produire des galettes, de la cassave ou des «tortillas »), absentes sur le site d'Eva 2, marquera ensuite une autre étape dans la consommation des Amérindiens, cette fois à l'Âge céramique.

\section{L'Âge céramique ancien : phases A et B}

Le site amérindien de Chemin Saint-Louis (CSL) est implanté sur la berge d'une terrasse holocène située sur la rive droite du bas-Maroni (Figure 1). Cette berge s'étend vers le nord et le sud le long du fleuve en constituant un site couvrant environ 15 hectares. Ce site de berge se marque par la présence d'une épaisse couche noire parsemée de mobilier archéologique jusqu'à une profondeur d'environ $1 \mathrm{~m}$ dans l'est de la parcelle (Figure 4a). Au-dessous de cette couche anthropique se trouvent les creusements liés à l'habitat des différentes phases d'occupation. Les datations au radiocarbone ont montré trois occupations majeures espacées dans le temps: une première vers 33001900 av. J.-C. (Phase 1), une deuxième entre 0 et 400 apr. J.-C. (Phase 2) et une dernière entre 900 et 1300 (Phase 3). La première et la deuxième phase représentant des périodes inédites jusqu'à présent dans l'ouest de la Guyane française (van den Bel 2012b). On constate par ailleurs que les Amérindiens n'ont pas occupé ce site en continu: il y a, en effet, des hiatus chronologiques non seulement entre les phases, mais aussi pendant ces dernières, notamment pendant les phases 1 et 3 . Concernant ces deux phases, on suppose que les populations ont persisté à vivre sur la berge, mais que le lieu exact de leur implantation a changé, comme le montre le site de La Pointe de Balaté, situé au nord de CSL et fournissant les mêmes mobiliers et datations en Phase 3. Les hiatus entre les phases 1 et 2 et les phases 2 et 3 sont bien marqués et suggèrent, eux, un abandon définitif. On peut en définitive considérer que le site de CSL a connu une longue trajectoire à travers la préhistoire du Bas-Maroni.

\section{Phase 1}

La dernière terrasse du Maroni (Terrasse IV) a été mise en place entre environ 10000 et 6000 ans avant nos jours ${ }^{7}$. Une fois que le Maroni a eu creusé son lit, il a commencé à déposer du sable lors des crues, ce qui a déclenché

7. On note que la formation de la Terrasse IV coöncide avec des événements climatiques importants comme la sécheresse du milieu de l'Holocène, reconnue partout en Amazonie et appelée la « Holocene Drought » (Bush et al. 2008, p. 1796 ; Mayle et Power 2008). 
Martijn M. vAN DEN BEL

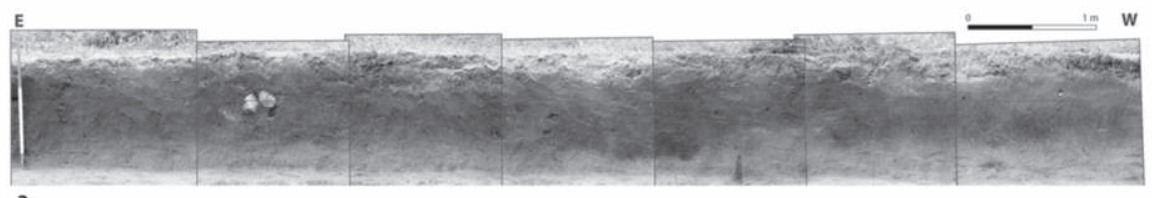

a.
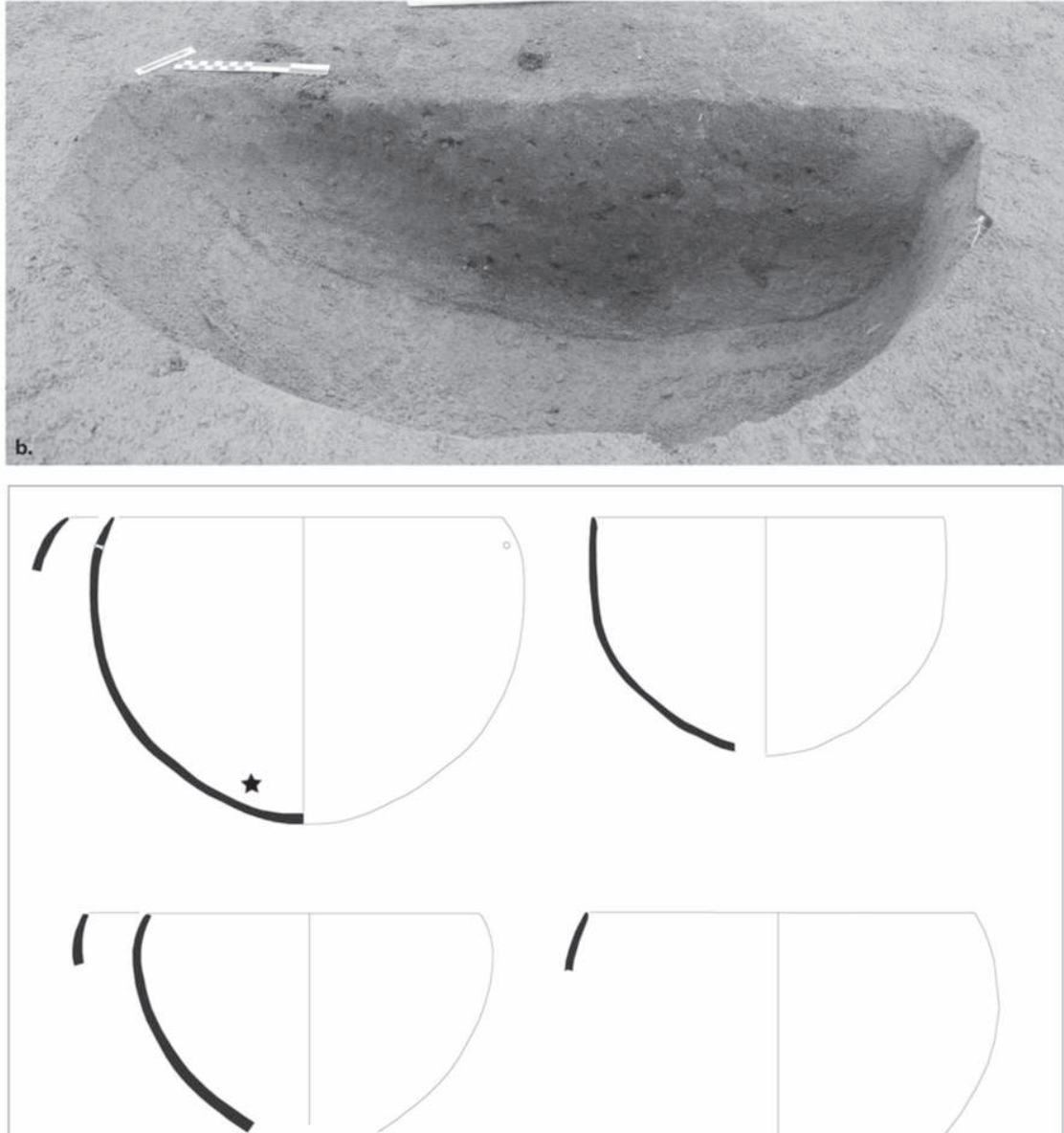

c.

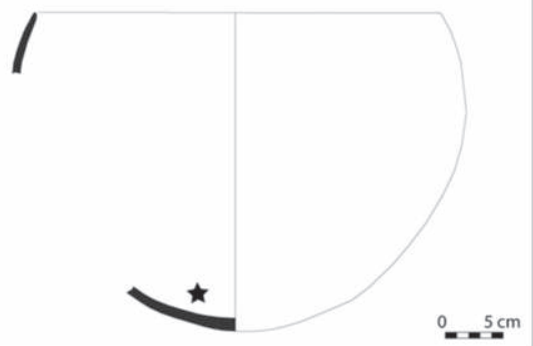

Fig. 4 - Le site de Chemin Saint-Louis : a. profil des terres noires (photo P. Texier), b. fosse à charbon daté à la Phase 1 (photo M. van den Bel), c. les céramiques anciennes de la Phase 1 : l'étoile indique les prélèvements de résidu noir pour analyse d'amidon (dessins par M. van den Bel). 
la formation d'une petite berge sur l'escarpement de la terrasse. En même temps, cela a engendré la formation d'une zone basse ou bassin, derrière la (nouvelle) berge. Une fois le Maroni revenu à un rythme plus calme, il y a en gros 4500 ans, les Amérindiens commencèrent à fréquenter ce lieu mais, à l'exception de deux fosses (ayant livré des dates ${ }^{14} \mathrm{C}$ se rapportant au régime calme du Maroni), nous n'avons pas trouvé d'artefacts. Un peu plus tard, la berge fut clairement occupée, comme en témoignent deux fosses charbonneuses situées sur le sommet de la berge (Secteurs 54 et 55), soit la partie la plus haute de la zone fouillée dont le méplat sommital se trouve plus au nord.

La nature de ces fosses demeure difficile à déterminer, mais elles sont interprétées pour l'instant comme des foyers. À quelques mètres du foyer F42 se trouvent deux autres fosses contenant chacune deux vases entiers déposés à l'envers et ayant fourni des dates contemporaines des foyers (2300 av. J.-C.) (Figure 4b). Il s'agit probablement de deux sépultures ce qui évoque, en combinaison avec les foyers, une véritable zone d'habitat à la fin du III ${ }^{\mathrm{e}}$ millénaire avant notre ère.

Les populations amérindiennes qui fréquentaient le site disposaient d'une céramique assez simple: des jattes sphériques avec du quartz concassé comme dégraissant (Figure 4c). Leur industrie lithique était fondée sur le débitage du quartz qui se ramassait vraisemblablement sous forme de galets sur les plages du Maroni pendant la marée basse. On observe une technique standardisée sur les galets de rivière pour la production d'outils sur (petits) éclats. L'usage de ces outils demeure difficile à définir malgré nos tentatives d'analyse microscopique. Cependant, la production d'outils sur éclats, comme sur le site d'Eva 2, semble le but principal qui se manifeste à travers les différentes qualités de quartz (Knippenberg 2012).

Une grande meule est aussi associée à cette période d'après sa position topographique et sa forme, analogue à d'autres exemplaires contemporains trouvés sur Eva 2. Cette meule a été utilisée sur trois faces et les granules d'amidon prélevés dans les fissures et les pores ont démontré la présence des espèces suivantes: Ipomoea batatas, Phaseolus sp. et Zea mays. En plus, incrustés dans la paroi d'un vase, on a pu déterminer les granules d'amidon de Maranta arundinacea, Ipomoea batatas et Zea mays, ainsi que ceux de Marantaceae et Calathea sp., sur un autre vase (Pagán Jiménez 2012). Pour l'instant, on ne connaît pas encore les façons de consommer ces plantes, mais elles furent vraisemblablement transformées par broyage et par cuisson afin de fabriquer une soupe ou une bouillie par exemple.

Cette phase ancienne concorde avec les résultats d'Eva 2 et PDM (voir supra), en sachant que nous n'avons pas trouvé d'amas de blocs de quartz ou encore d'amas de coquilles dans le périmètre de la fouille ${ }^{8}$. Les récipients en céramique

8. Toutefois ce type d'amas est apparu lors d'un diagnostic sur une parcelle à l'est du chemin de CSL (Mestre 2008, p. 21). 
de cette phase semblent avoir été utilisés pour la préparation de la nourriture et cela peut expliquer leur simplicité et l'absence d'éléments décoratifs. En Guyane, de la céramique contemporaine a été trouvée pour l'instant seulement sur le site d'Eva 2 mais, dans ce cas, il s'agit principalement d'écuelles ou de formes de petite taille. L'ensemble de ces céramiques anciennes rappelle bien la phase Alaka au Guyana et la tradition Mina au Brésil. Même s'il est difficile encore de conclure à une relation culturelle entre les deux, il apparaît évident que la céramique ancienne était courante sur le plateau des Guyanes il y a 4000 ans.

À la fin de la Phase 1 on se retrouve avec deux dates qui relient les Phases 1 et 2. Étant donné l'extension de la terrasse, on peut imaginer que ces dates correspondent à une suite de la Phase 1 mais ponctuelle. Comme déjà évoqué, il est possible que les habitats de cette phase « intermédiaire » aient été situés effectivement sur une autre partie de la terrasse. Le Maroni pouvait alors déborder encore régulièrement et les habitats pouvaient être, de ce fait, assez temporaires.

\section{Phase 2}

La Phase 2 se distingue par une occupation longue et continue confirmée par la présence d'une couche de terre noire épaisse. Outre une séquence serrée de datations, le type de structure (trous de poteau et fosses à dépôt de céramique) et le mobilier céramique présentent une homogénéité extraordinaire sur la surface fouillée. La série des dates suggère trois zones d'habitat matérialisées par des fosses à dépôts qui se trouvent au pied et autour du sommet de la berge. À travers cette séquence, on peut supposer des localisations espacées spatialement et chronologiquement, représentées par les Phases 2a-c. On observe que les structures s'entrecoupent à peine et que les fosses à dépôts sont plus ou moins groupées par dates. On peut en fait définir l'occupation comme un palimpseste d'habitats amérindiens marqués, chacun, par une grande zone de dépotoir. Cette succession d'habitats et l'accumulation de mobilier céramique et lithique ainsi que les matériaux végétaux et périssables (bois des poteaux, toitures, déchets alimentaires, excréments) ont enrichi le sol de la zone habitable et engendré le développement de la terre noire. La présence humaine sur le site a également provoqué un ruissellement local et un déplacement de sédiment du sommet vers les zones basses : à la fin de l'occupation, on estime que le bassin naturel avait été comblé avec du sable de ruissellement en formant un sol anthropique et cumulatif. Les résultats des analyses chimiques montrent une (légère) différence avec ceux de l'Amazonie centrale ce qui a conduit à proposer une terre noire propre à la Guyane, appelée " Guiana Dark Earth » (Brancier 2009 ; Brancier et al. 2014 ; Figure 4a).

La Phase 2 évoque un village permanent sur une longue durée (environ quatre siècles) au début du I ${ }^{\mathrm{er}}$ millénaire de notre ère, sans interruption majeure, étiré sur une terrasse holocène du Maroni (Phases 2b-c), avec une étape d'habitat précurseur 
(Phase $2 \mathrm{a})^{9}$. La céramique trouvée dans la zone orientale (Phase 2a) a livré des petites écuelles carénées avec un engobe rouge à l'extérieur (souvent appliqué entre la lèvre et la carène). L'occupation de la Phase $2 \mathrm{c}$ se situe vers l'escarpement de la terrasse à l'ouest où on trouve également des écuelles avec un engobe rouge ce qui prouve la forte homogénéité de la Phase $2 b$-c, couvrant quatre siècles.

L'étude céramique a permis d'établir un registre conséquent de huit formes populaires : les formes hyperboloïdes y sont éloquentes (Figure 5). La position de la carène change ainsi que l'inflexion de la partie supérieure (surtout parmi les écuelles), mais l'ensemble demeure principalement caractérisé par cette forme globale et non par les décors. On observe que les décors ne représentent que $6,7 \%$ de 1 'ensemble céramique du CSL et que l'application d'un aplat (surtout rouge) en constitue l'essentiel (92\% des décors).

Le reste correspond à d'autres types de décors comme les incisions, les ponctuations, le piquetage ou le modelage, ce dernier mode étant le moins fréquent. Pour caractériser la production céramique de cette deuxième occupation, on retiendra les formes en "cloche », les pâtes sableuses, les bases bombées à l'intérieur et les engobes rouges à l'extérieur. On peut ajouter encore trois formes qui jouent un rôle de marqueurs : les plats à bords creux avec engobe rouge à l'intérieur, le bol à col avec engobe rouge à l'extérieur, les pots bichromes à col multi-caréné.

Les séries de CSL Phase 2 n'ont pour l'instant pas d'équivalents contemporains dans la littérature et les quelques collections privées connues sur le Maroni. Il s'agit d'un ensemble inédit, mais bien calé par les datations ${ }^{14} \mathrm{C}$. On a cherché à déterminer les espèces végétales présentes sur des écuelles et des plaques à cuire afin de mieux connaître le régime alimentaire. Sur les plaques à cuire, on a identifié les graines d'amidon du piment domestiqué (Capsicum sp.), des patates douces (Ipomoea batatas) et du maïs (Zea mays). Ce type d'objet en céramique est communément nommé « platine à manioc », mais il semble qu'à l'époque précolombienne ces platines aient été utilisées pour cuire ou pour chauffer plusieurs types d'aliments et pas uniquement le manioc. Il faudra bien évidemment plus d'échantillons de diverses périodes pour déterminer l'usage des plaques à cuire. Sur les écuelles ont été trouvées les espèces suivantes: patates douces (Ipomoea batatas), Marantaceae, Maranta arundinacea, Manihot sp., Manihot esculenta, Fabaceae, Phaseolus vulgaris et lunatis, Zea mays. Ici donc, le manioc est bel et bien présent et il coexiste clairement avec le maïs, les patates douces et les haricots (Pagán Jiménez 2012).

9. Les datations au radiocarbone formant la Phase 2 présentent une série homogène à partir de l'an I (Phase 2b-c), mais remontent peut-être jusqu'à 300 av. J.-C. La céramique de la première phase (Phase 2a), pour sa part, s'avère différente par sa pâte mixte et ses formes, mais il est possible qu'il s'agisse d'une intrusion de la Phase 3. Par ailleurs, les dates de la Phase $2 \mathrm{~b}$ se trouvent toutes dans la zone orientale de la fouille, soit le bassin de la terrasse ou la zone basse. 
Martijn M. vAN DEN BEL

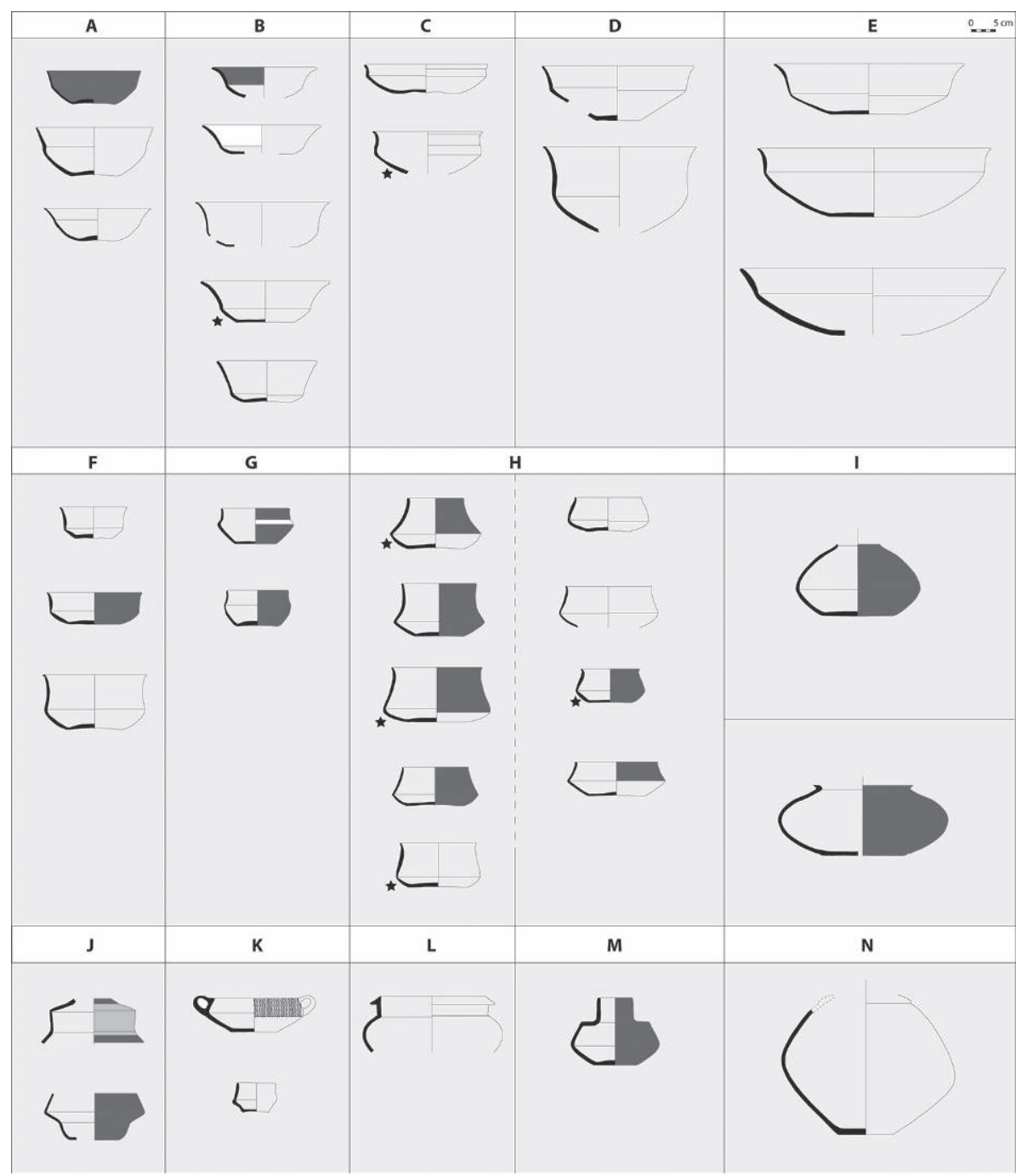

Figure 5. Les formes principales du site Chemin Saint-Louis : Formes A-H Phase 2b-c ; Formes I-J Phase 2a et Formes K-N Phase 3. L'étoile indique le récipient des prélèvements de résidu noir pour l'analyse d'amidon (dessins par M. van den Bel). 
Sur la base de ces premières données, on peut supposer que les préparations alimentaires ainsi que les ingrédients ont fluctué avec le temps et que ce qu'on observe aujourd'hui n'eut pas forcément cours à une date ancienne. Ces questions constituent un champ d'études importants pour la Guyane et sur la paléo-cuisine et la paléobotanique des populations amérindiennes (Rostain 2012b, 2015 ; van den Bel 2015a).

\section{Phase 3}

Cette phase, attribuée à l'Âge céramique tardif (voir infra), se situe entre 950 et 1270 apr. J.-C. Les dates, le type de structures et le mobilier céramique présentent une hétérogénéité qui rend difficile l'interprétation de cette occupation. Cette dernière occupation forme un binôme avec celle de La Pointe de Balaté (LPB) qui présente les mêmes caractéristiques. Ce dernier site se trouve sur la même terrasse holocène à environ 1,5 km de CSL, mais les deux sites sont séparés par la crique Balaté (Briand et al. 2016).

La céramique à formes ouvertes avec un dégraissant végétal (kwepi) ou à la chamotte et avec une pâte d'aspect savonneux domine cette double occupation. Géographiquement et chronologiquement, cet ensemble devrait s'intégrer dans les séries céramiques Barbakoeba du littoral oriental du Suriname (Boomert 1993). Cependant plusieurs éléments caractéristiques du complexe surinamien ne sont pas présents à CSL et LPB ; il pourrait s'agir d'une variante locale comme le site funéraire contemporain d'Awala Yalimapo à l'embouchure du Maroni (Coutet, Romon et Serrand 2014). La présence de pots toriques sur nos sites, portant des incisions géométriques complexes, renvoie au complexe Koriabo, très répandu dans les Guyanes lors de l'Âge céramique tardif (Boomert 1986, 2004). On doit remarquer ici que ces deux complexes céramiques tardifs se manifestent souvent sur le même site (Boomert 1993, p. 207-208), mais l'absence de plus de datations radiocarbones pour le Barbakoeba ne permet pas pour l'instant d'établir une chronologique absolue. Cependant, les sites de LPB, CSL Phase 3 et Crique Sparouine (infra) proposent un schéma chronologique dans lequel le Koriabo serait postérieur à Barbakoeba.

\section{Conclusion}

Chemin Saint-Louis est donc un site clé pour l'archéologie précolombienne de la Guyane française occidentale. Sa fourchette chronologique étendue, sa position géographique et géologique et sa taille témoignent d'un site d'importance du Bas-Maroni. L'assemblage céramique se répartit en trois ensembles culturels dont les Phases 1 et 2 sont des occupations anciennes inédites jusqu'à présent pour cette région. À partir des résultats d'Eva 2 et de la Phase 1 de CSL, on propose d'identifier un complexe céramique de Balaté correspondant aux ensembles céramiques anciens ou formatifs de la Guyane. Les séries céramiques 
de la Phase 2, également une occupation de l'Âge céramique ancien inédite, seront appelées Saint-Louis. Le premier complexe (Balaté) sera attribué à la Phase A de l'Âge céramique ancien et le second (Saint-Louis) à la Phase B du même Âge céramique ancien.

\section{L'Âge céramique tardif}

Les sites de cette époque sont les plus nombreux sur la bande littorale guyanaise et par conséquent cette période peut se présenter comme l'apogée de l'occupation précolombienne de la Guyane. Cependant, un biais peut exister et tenir à la fois à l'intensité des recherches dans la région et au fait que les zones basses de la côte étaient impropres à l'installation humaine. On présentera ici quatre sites tardifs dont un sur le Maroni, un sur la bande littorale à Iracoubo et deux sur l'île de Cayenne (un en hauteur, l'autre en bord de mer).

\section{Le site de Crique Sparouine}

Le site de Crique Sparouine est situé au sommet d'un petit morne précambrien atteignant $30 \mathrm{~m}$ de haut et d'une surface de $7500 \mathrm{~m}^{2}$, qui surplombe la Crique Sparouine, dans l'arrière-pays du Bas-Maroni (Figure 1). La répartition pondérale du mobilier lithique et céramique fait apparaître deux aires liées aux activités avec outils lithiques mais comprenant aussi deux zones de dépotoirs céramiques. Dans la partie sud, sur le sommet du méplat, du décapage $\left(2000 \mathrm{~m}^{2}\right.$ environ) se trouve un ensemble de trous de poteaux constituant probablement une structure (carbet 1), une concentration d'outils lithiques (Zone 2) et un dépotoir de céramique secondaire (dépotoir C) (Figure 6).

La couche archéologique a aussi révélé des dépôts en céramique, présents uniquement dans cette zone méridionale. On suppose qu'il s'agit de dépôts d'abandon quand cette partie du site a fonctionné comme plaza lors de sa dernière phase d'occupation. L'ensemble des faits anthropiques et des dépotoirs situés dans le nord du périmètre de décapage est considéré comme la dernière occupation du site avec un dépotoir principal (dépotoir A) et un autre plutôt secondaire (dépotoir B), près duquel sont apparus des trous de poteaux. L'implantation d'une deuxième structure (carbet 2) est envisageable à cet endroit et il pourrait bien être contemporain du premier carbet en constituant avec lui un village de deux carbets. Cependant, entre ces deux carbets, la présence d'une dernière ou première structure (carbet 3 ) est possible. En fait, sa configuration est la plus évidente des trois, car on a observé plusieurs poteaux porteurs de plus de $30 \mathrm{~cm}$ de profondeur formant clairement des angles. On peut imaginer là un carbet d'environ $400 \mathrm{~m}^{2}$ en surface.

Ces éléments permettent de conclure que le site de Crique Sparouine fut un site d'habitat de plein air. Les datations s'échelonnent entre 1000 et 1400 apr. J.-C. 
Nouveaux apports sur l'archéologie du littoral de Guyane

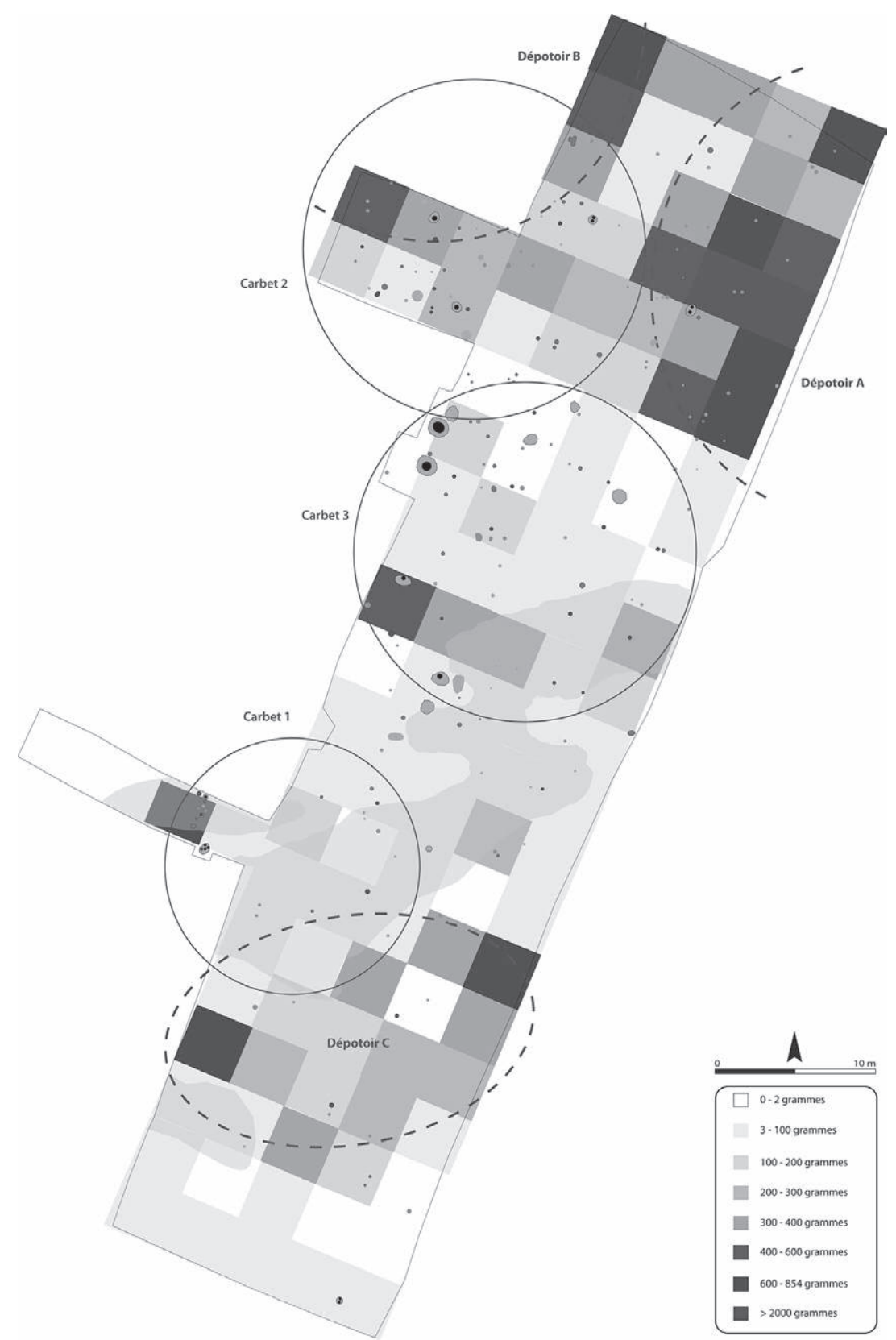

Fig. 6 - Répartition pondérale de la céramique et des structures en creux du site Crique Sparouine. Les emplacements des Carbets et Dépotoirs ont été indiquées par des cercles fermés et pointillés respectivement (plan par M. van den Bel). 
et suggèrent une occupation assez longue. L'assemblage céramique, pour sa part, se divise en deux ensembles bien définis, issus notamment des fosses (sépultures?): un premier ensemble à récipients sphériques à pâte à surface savonneuse (Formes A-D) et un deuxième ensemble à pots toriques et à jattes florales (Formes E-F), autrement dit le Koriabo (Figure 7). Le premier ensemble ne connaît que peu de parallèles (dans les fouilles ou dans la littérature) sur le littoral et à l'intérieur. Il se présente plutôt comme un groupe de nouvelles séries céramiques. La discussion qui suit, comme nous l'avons évoqué auparavant pour le site de LPB et comme nous le verrons plus loin pour Cimetière paysager Poncel (CPP), envisage la possibilité de deux phases d'occupation (par des groupes humains différenciés) ou d'une seule occupation dont la population aurait eu un ensemble de récipients particuliers dans un secteur du site. Une ambigüité comparable a été observée aussi sur le site de la Pointe Morne à Saint-Georges de l'Oyapock où un site koriabo « remplace » un site funéraire Aristé récent (Mestre et Hildebrand 2011).

Un site koriabo?

Cette hypothèse renvoie clairement au problème koriabo qui concerne tout le plateau des Guyanes. Aujourd'hui environ 85 sites ont révélé du mobilier typiquement koriabo dans les Guyanes, encore que la plupart soient connus à travers des ramassages de surface, plusieurs sondages de quelques mètres carrés ou encore par des vases entiers trouvés dans les sauts des fleuves. Très peu de sites ont été fouillés sur des surfaces de $100 \mathrm{~m}^{2}$ et plus. Cela a eu pour effet une focalisation sur la céramique koriabo décorée (Formes E et F) et a donné lieu à beaucoup de spéculations sur les origines du phénomène koriabo. Sur le site de Crique Sparouine, on peut se demander si les vases koriabo découverts sont des pièces d'échange parvenant à un établissement qu'il faudrait rattacher à un complexe céramique inconnu, ou s'il s'agit d'un véritable site koriabo d'habitat avec sa céramique (van den Bel 2010a).

En effet, si on accepte le site de Crique Sparouine comme un site koriabo propre, alors la totalité des formes céramiques obtenues à cet endroit serait Koriabo comme le suggère Boomert (1986). En revanche, si on considère ce site comme un site non koriabo, les récipients autres que ceux attribuables clairement au Koriabo correspondraient à un complexe inconnu à ce jour. Le répertoire des jattes à bord sinueux (Forme $\mathrm{A}$ ), les bouteilles à col divergent (Forme $\mathrm{B}$ ), les formes ouvertes (Forme C) et les vases naviformes (Forme D) formerait un complexe encore non identifié. Finalement, on peut aussi envisager deux occupations successives : une occupation dont la céramique demeure encore inconnue, suivie par une occupation ou une présence koriabo en suivant les datations tardives du Koriabo dans cette région. 


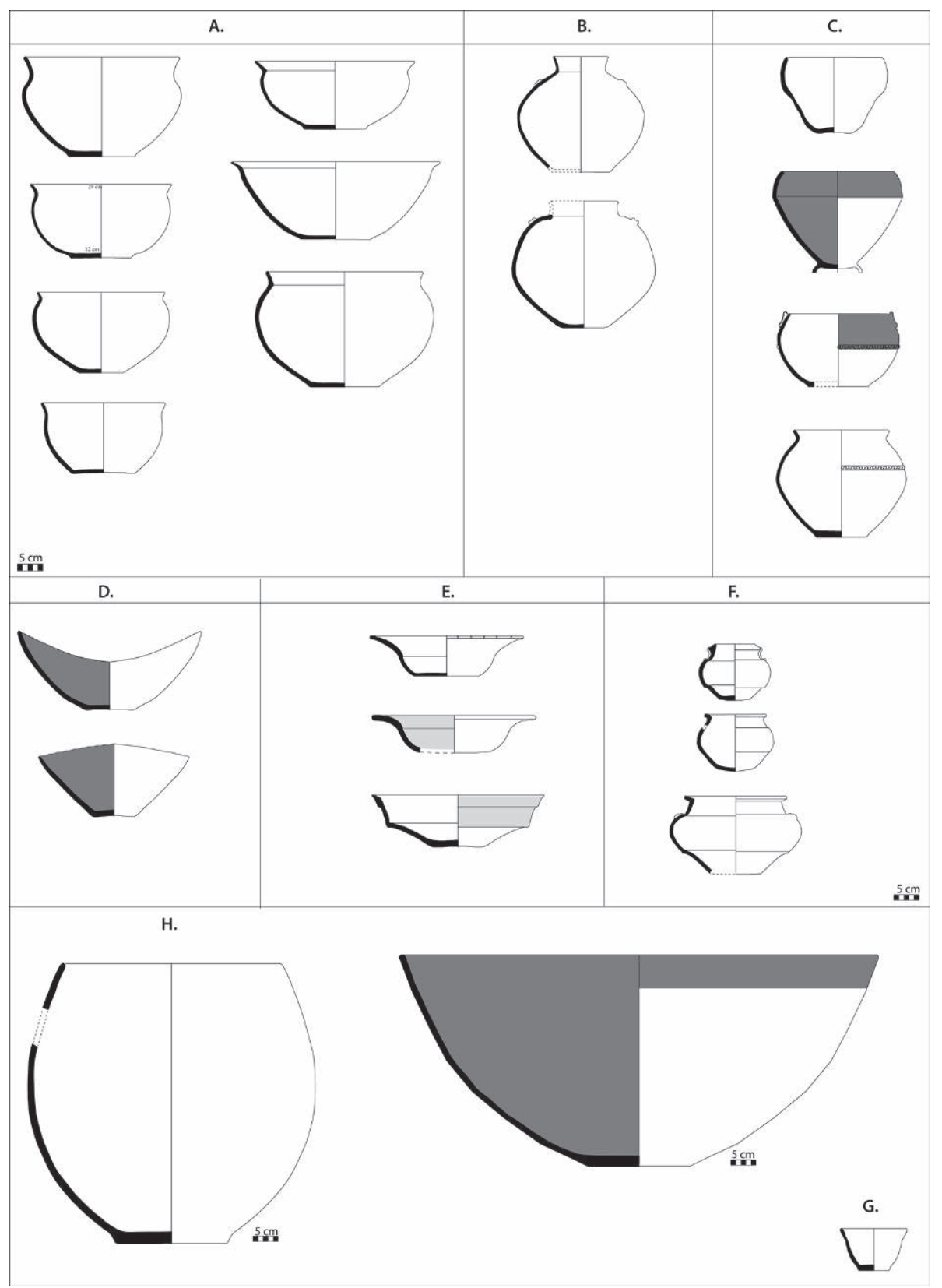

Fig. 7 - Les formes principales A-G du site

Crique Sparouine (dessins par M. van den Bel). 


\section{La nécropole d'Iracoubo}

Le site funéraire de Sables Blancs Est est localisé à l'ouest du bourg d'Iracoubo sur une barre pléistocène (Figure 1). Deux concentrations d'urnes ont été découvertes, dont la plupart se trouvaient à environ $30 \mathrm{~cm}$ de profondeur. Le premier ensemble (Zone A) concerne 41 dépôts céramiques répartis dans 23 fosses, ainsi que deux concentrations de tessons de céramique disposés à plat et quelques trous de poteaux. Cet ensemble n'a pas été fouillé intégralement et se poursuit vraisemblablement sur la parcelle adjacente à l'ouest (Figure 8). La deuxième concentration (Zone B) contient 33 céramiques réparties dans 16 fosses, ainsi qu'une concentration de tessons à plat et cinq trous de poteaux dont quatre d'entre eux forment une structure carrée. Un échantillon de charbon, provenant d'un récipient de la Zone $\mathrm{B}$, a livré une datation radiocarbone située vers la fin du $\mathrm{I}^{\mathrm{er}}$ millénaire de notre ère (van den Bel 2009, 2015c) ${ }^{10}$.

\section{Les modes de déposition}

Les récipients étaient remplis d'un sédiment local sablo-argileux d'une couleur grise. Cependant, quelques récipients dans la Zone B étaient remplis de sable blond, intrusif dans les barres pléistocènes et correspondant plutôt à un sable rapporté d'un chenier holocène afin de couvrir les urnes et formant peut-être une forme de tertre artificiel. Dans chaque ensemble, plusieurs types de dépôts céramiques et différentes combinaisons de dépôts à l'intérieur d'une même fosse ont été identifiés. Les dépôts céramiques sont agencés de cinq manières différentes et répartis en deux ensembles funéraires :

- Type 1: un récipient entier posé sur le fond de la fosse ronde ou ovoïde et recouvert d'un autre récipient à l'envers ;

- Type 2: un récipient entier posé à l'envers au fond d'une fosse ronde ou ovoïde ;

- Type 3 : un grand fragment de céramique (bord, fond ou moitié de vase) déposé dans une fosse ronde ou ovoïde ;

- Type 4: un bon nombre de grands tessons entassés dans la fosse ;

- Type 5: des petits récipients posés au fond d'une fosse carrée ou rectangulaire dont les parois sont délimitées ou renforcées par des grands fragments de platines donnant l'idée d'un « coffre $»{ }^{11}$.

10. Une autre zone d'urnes se trouve plus au sud de la partie fouillée par l'Inrap et a été gelée par le Service d'archéologie de Guyane. Six échantillons céramiques pris dans cette zone ont été testés par thermoluminescence fournissant deux fourchettes chronologiques: une première entre la fin du $\mathrm{IX}^{\mathrm{e}}$ et la fin du $\mathrm{X}^{\mathrm{e}}$ siècle de notre ère et une deuxième entre la fin du XII ${ }^{e}$ et le début du XIII ${ }^{e}$ siècle de notre ère (Gassies et Lemaire 2006). Cependant, ces dates ne constituent que des estimations.

11. D'autres types de dispositions ont été observés ponctuellement, mais ces cinq types sont les plus populaires des deux ensembles funéraires. Quatre concentrations de céramiques 
Nouveaux apports sur l'archéologie du littoral de Guyane

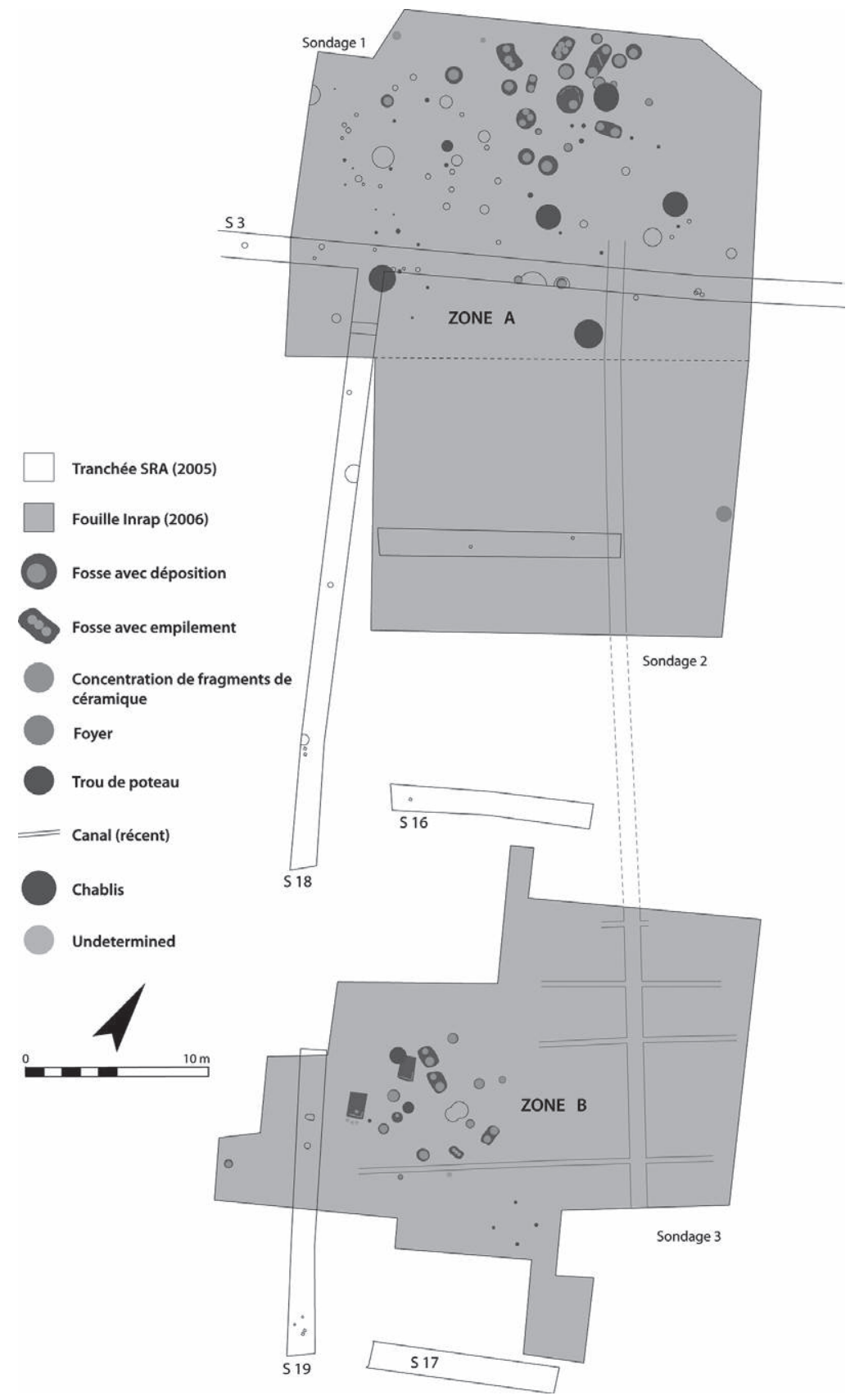

Fig. 8 - Plan des fouilles à Sables Blancs Est montrant les Zones de fouille A et B (plan par M. van den Bel). 
Martijn M. vAN DEN BEL

Les 39 fosses détectées sont liées aux dépôts. Elles ont été creusées jusqu'au substrat vierge, constitué d'une argile sableuse et bariolée par l'oxyde de fer. Si les fosses sont parfois difficiles à détecter, la taille du récipient qu'elles contiennent permet souvent de déterminer leurs dimensions. Le remplissage de chaque fosse est souvent moins foncé que celui des vases, et contient parfois quelques tessons. La plupart des fosses étaient remplies de goethite, ce qui pourrait indiquer qu'elles ont été ré-ouvertes ou que le récipient n'était que partiellement enterré. S'il y a plusieurs vases dans une même fosse, la forme du creusement peut être irrégulière, ce qui conforte l'idée de la réouverture: une fosse de forme irrégulière ou polymorphe peut être le résultat de creusements successifs et/ou de la réouverture d'une même fosse. Les ré-creusements et les recoupements des fosses montrent nettement que les Amérindiens géraient parfaitement cette zone à dépôts et avaient la connaissance de la distribution spatiale des fosses et de leurs récipients.

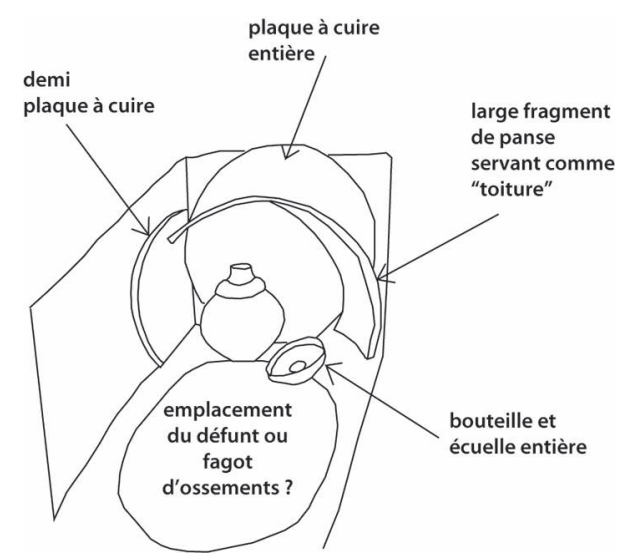

Fig. 9 - Interprétation de la fosse F 21 dans la Zone B comme maison du défunt (dessin par M. van den Bel).

Les quelques fosses carrées, toutes situées au milieu d'une concentration, méritent plus d'attention, notamment la fosse F 21 de la Zone B (Figure 9). Les parois de cette fosse étaient partiellement délimitées par des platines placées debout: on trouve là une platine (diamètre $80 \mathrm{~cm}$ ) et une demi-platine placée perpendiculairement, une bouteille entière avec un col évasé (hauteur $23 \mathrm{~cm}$ ) déposée sur le fond de la fosse, une petite écuelle peinte en rouge à l'intérieur et avec un motif géométrique peint en blanc sur fond rouge (plages horizontales et verticales alternées) sur le bord. Cet ensemble fut recouvert par un grand fragment de panse qui servait de toit ou de couverture, le tout constituant une espèce de maison ou carbet.

\section{L'interprétation}

Avant tout, il faut constater que ces concentrations de creusements sont, pour la plupart, des fosses contenant seulement aujourd'hui des vases en céramique. Aucun ossement humain n'a été découvert, ni à l'intérieur des vases, ni dans

ont été trouvées sans fosse (visible) et elles sont considérées comme des concentrations de tessons à plat. Néanmoins, ces concentrations peuvent être liées à l'ensemble funéraire, s'agissant de fragments cassés. 
les remplissages des fosses ${ }^{12}$. Ce sont donc les différents types de dépôts et leur distribution spatiale concentrée qui suggèrent un ensemble funéraire. Si les vases et les petites fosses évoquent plutôt des sépultures secondaires (Types 1-4), les fosses carrées ou coffrées (Type 5) ont pu quant à elles contenir des inhumations primaires mais aussi peut-être le dépôt de fagots d'ossements. L'absence sur place d'autres vestiges, tels que des puits, d'autres fosses, des trous de poteau, une couche archéologique épaisse (malgré le nivellement), laisse supposer que la zone a été fréquentée et utilisée exclusivement comme site funéraire : il s'agit d'un site à l'écart des habitations. Ces dernières se trouvent en bordure de la RN 1, dans une zone sondée par l'équipe de Rostain en 2007 (Rostain 2015).

La seule vraie construction identifiée concerne les quatre trous de poteau à quelques mètres de la Zone B ainsi qu'une fosse de combustion entre les deux zones. Il est possible que ces éléments soient en relation avec les pratiques funéraires du groupe qui a utilisé cet espace sépulcral. On imagine que les corps ont pu être décharnés à l'air libre, sur place ou dans un endroit déterminé à l'extérieur du site. Puis les ossements étaient récupérés et probablement traités, avant d'être déposés dans une urne. Les dimensions de certains récipients indiquent que le squelette ou quelques os sélectionnés ont pu être brisés ou concassés avant d'y être déposés. De telles pratiques étaient encore attestées à l'époque historique dans les Guyanes (Roth 1924). Il semble, par ailleurs, que les dépôts de fragments de poterie de Type 4 soient également le résultat de coutumes liées à la mort. Ce type de dépôt n'aurait contenu ni recouvert aucun reste humain, mais aurait fait partie d'une cérémonie d'enterrement ou de lever du deuil : les Wayana sub-actuels brisent les céramiques et détruisent les biens du défunt pendant la cérémonie d'enterrement (de Goeje 1943, p. 36).

Un autre point particulier mérite d'être souligné: les récipients sont simples (SM I-II : $78 \%$ ), rarement décorés (10\% ; van den Bel 2015d); ils sont très différents des urnes polychromes, souvent anthropomorphes, des sites funéraires Aristé de l'est de la Guyane. En fait, les urnes de Sables Blancs Est ressemblent à des récipients d'usage courant et on peut se demander si elles furent fabriquées spécialement pour un usage funéraire ou s'il s'agit de récipients domestiques réutilisés à cette fin. Enfin, quelques rares décors évoquent une attribution culturelle au complexe Barbakoeba.

Les différents types de dépôts pourraient évidemment correspondre à des pratiques funéraires distinctes, variables selon le statut du défunt, ce qui indiquerait une stratification sociale de la communauté. L'existence de deux ensembles funéraires séparés appuie peut-être cette hypothèse, chaque unité sociale pouvant être identifiée car enterrée dans un lieu spécifique. C'était le cas encore

12. Les résultats des analyses paléo-parasitologiques ont été aussi négatifs dans ce milieu néotropical, le sol étant trop acide. On tente actuellement des analyses chimiques afin de déterminer le taux de phosphates. 
au début du $\mathrm{Xx}^{\mathrm{e}}$ siècle chez les Palikur de la rivière Urucauá, au nord de l'État d'Amapá du Brésil (Nimuendajú 1926). Un cimetière se marque également dans le paysage et doit être identifiable par les membres d'une même ethnie. Il faudra alors des signes visibles en surface, comme des fosses laissées ouvertes, des urnes enterrées partiellement ou des petits monticules (Guapindaia 2001, p. 167). La présence du sable blond dans quelques vases de la Zone B indique peut-être l'existence d'un tertre, signalant un groupement d'urnes correspondant à un clan ou à une famille. D'ailleurs, le propriétaire de la parcelle a signalé au SRA qu'il avait aplani une butte de sable avant le passage des archéologues en 2004, pour combler une zone humide contiguë. Si l'on poursuit ce raisonnement, le dépôt en coffre (Type 5) pourrait correspondre à la sépulture d'un chef ou d'un membre principal d'une famille ou d'un clan. La fosse coffrée peut même avoir une signification symbolique puisqu'elle paraît reproduire une maison ${ }^{13}$. Le défunt important aurait été déposé de façon primaire dans une " maison », accompagné de céramiques et d'autres offrandes pour la vie dans l'au-delà. La mort et les conceptions qui s'y rattachent sont des aspects qu'on ne saurait négliger pour comprendre les comportements sociaux amérindiens précolombiens, mais ils restent cependant difficiles à saisir à partir du seul mobilier archéologique.

\section{L'île de Cayenne: Rorota et Poncel}

Les deux sites fouillés sur l'île de Cayenne, PK 11/Rorota et Cimetière paysager de Poncel (CPP), sont contemporains et voisins (Figure 1). CPP se localise sur une hauteur précambrienne au milieu d'un marécage qui forme l'arrièrepays du site du Rorota, situé sur un cordon pléistocène dans l'Anse de Rémire.

\section{Les datations}

Les deux sites ont livré 24 datations ${ }^{14} \mathrm{C}$ pour une occupation principale qui s'étale grosso modo entre 900 et 1500 . En dehors de cette fourchette, les deux sites ont aussi livré des datations plus anciennes qui évoquent une présence ou une occupation antérieure, notamment de l'Âge archaïque pour Rorota et de l'Âge céramique ancien Phase B pour CPP. Dans ce second cas, on a découvert une fosse profonde contenant du mobilier caractéristique et attribuable au type Ouanary encoché. La présence datée sur l'île de Cayenne de ce mobilier révèle une occupation ancienne qui, jusqu'à présent, n'avait été reconnue que dans le bassin de 1'Oyapock (Rostain 1994b, 2012a). Rostain a en effet proposé un schéma régional pour le développement de l'Aristé ancien auquel il rattache ce type de céramique ancienne. La datation obtenue à CPP, mais aussi celles

13. Les Palikur contemporains utilisent d'ailleurs le même mot pour désigner l'urne et la maison (Petitjean Roget 1983 ; van den Bel 1995). 
d'autres sites fouillés sur les hauteurs de la rivière de Kaw et de l'Oyack (Favard et Pointe Maripa), semble indiquer en fait que le mobilier céramique encoché a pu précéder l'Aristé ancien de l'embouchure de l'Oyapock.

La présence de matériel ancien sur l'île de Cayenne est intéressante, car elle interroge une fois de plus sur l'ancienneté de l'occupation du lieu (à l'Âge céramique ancien, c'est-à-dire avant 900 de notre ère), mais aussi sur l'accessibilité de Cayenne, notamment par rapport à la formation Moleson. Le site du Rorota a permis de reconstituer les dernières étapes de la genèse et de l'évolution du littoral de Cayenne (Seurin 1976). L'étude stratigraphique a servi à définir une régression intermédiaire, calée entre deux transgressions, dont la dernière « se situerait après le Flandrien (alias Demerara), c'est-à-dire il y a quelques siècles, vers le Haut Moyen Âge » (Seurin 1976, p. 12). Cela correspond bien avec la datation au radiocarbone la plus ancienne obtenue ( $910 \pm 30$ avant l'actuel) pour le début de l'occupation tardive. À une échelle plus large, cela concorde aussi avec l'Holocène récent du Suriname (Brinkman et Pons 1968); ainsi l'occupation humaine du cordon du Rorota, voire de la bande littorale de l'Holocène tardif, ne fut possible qu'après la transgression de Moleson (500 av. J.-C.-700 apr. J.-C. ; Versteeg 1985 ; Palvadeau 1999, p. 32). En suivant cette chronologie géologique, Palvadeau (1999, p. 86) a également pu démontrer que la fourchette des dépôts P4 (Phase Moleson sic) à la hauteur de la Savane de Matiti (à l'est de Kourou) s'échelonne entre 700 av. J.-C. et 1500 apr. J.-C., en couvrant toute la période ancienne. L'installation humaine sur le cordon du Rorota se trouve alors dans un milieu soumis à l'influence de la mer, avec des bras de mers et des salines dans ses environs.

Finalement, l'Âge céramique récent correspond aussi partiellement au paléofeu de la Phase X (il y a 750-1 000 ans environ), telle qu'elle a été définie par Christophe Tardy pour plusieurs régions de la Guyane (1998, p. 237, 256). Cette période sèche (1000-1250 apr. J.-C.) se manifeste partout sur le continent sudaméricain, mais se confond facilement avec les activités humaines liées au feu: « la pression humaine sur le paysage est de plus en plus importante [Holocène récent] et est parfois susceptible de venir brouiller l'image des environnements naturels » (Tardy 1998, p. 251).

\section{Les structures en creux}

La surface fouillée d'environ $1000 \mathrm{~m}^{2}$ pour le site du Rorota n'a pas livré des creusements anthropiques autres que quelques trous de poteaux, mais le site de CPP, fouillé sur presque $6000 \mathrm{~m}^{2}$ a livré plus de 200 structures. Ce site correspond à un habitat avec une couche anthropisée et différents types d'enfouissements (trous de poteaux, fosses à dépotoir et à inhumation) qui se regroupent sur le sommet du morne. Cependant, autour du sommet, notamment vers l'est et le sud, on trouve des ensembles de fosses qui évoquent des habitats 
secondaires ou des lieux d'activités. Malheureusement, les datations ne permettent pas de saisir un ordre chronologique entre les différents ensembles définis. Le site paraît modeste si on compare la quantité de mobilier céramique et le nombre d'enfouissements à la surface sommitale. En revanche, l'abondance (relative) de meules et d'objets de mouture souligne la possibilité d'un habitat à activités ponctuelles, mais répétitives et persistantes.

Mises à part les fosses à dépotoir, les fosses dites « allongées » nous interrogent sur leur fonction: s'agit-il de fosses sépulcrales? Ainsi, une telle fosse allongée (rectangulaire) contenait des récipients en céramique, complets ou brisés, qui semblent bien avoir été déposés volontairement (Figure 10). La forme générale de la fosse et ses dimensions ( 170 × 50 × $30 \mathrm{~cm}$ environ) évoquent un corps humain en position allongée qui aurait été accompagné de vases entiers situés au niveau des pieds ou de la tête, ainsi que de fragments de poterie qui auraient été posés sur le corps comme une couverture. Toutefois, l'absence d'ossement (en position primaire ou secondaire) dans ces fosses interdit d'assurer qu'il s'agissait de fosses funéraires. Pour vérifier la présence originale d'un cadavre, on a soumis le sédiment issu d'une des fosses à des analyses paléo-parasitologiques: les résultats se sont avérés négatifs, mais c'est peut-être la conséquence de l'acidité du sol (note 12).

Malgré l'absence d'un cadavre avéré dans chacune de ces fosses, il faut remarquer la présence systématique de ce type de fosses allongées et remplies de céramiques sur l'île de Cayenne à partir de la fin du I $^{\text {er }}$ millénaire de notre ère, les premières observations remontant au diagnostic de Katoury (Jérémie, Mestre et Cazelles 2002). D'autres exemples suivirent, quelques années plus tard; les fouilles préventives sur Mombin 2 et 3 et Chennebras montrèrent une organisation spatiale groupée de plusieurs fosses sur un espace restreint et, pour la plupart, orientées selon des axes différents (Delpech 2010, 2015, 2017 ; Seguin 2017). Un axe d'orientation des fosses semble pourtant avoir été privilégié au sommet de CPP : nord-sud, mais il existe d'autres dispositions et orientations selon les lieux et/ou les types de site. On notera aussi, toujours au sommet de CPP, la présence de plusieurs dépôts de vases entiers placés à l'envers, ce qui évoque un autre mode d'enterrement (funéraire ou non). Il pourrait donc y avoir eu coexistence de fosses allongées et de dépôts avec céramique à l'envers comme à Iracoubo... En fait, la fonction de ces derniers dépôts céramiques demeure obscure sans détermination du contenu de la fosse. Dans ce cas précis, on pourrait proposer, par analogie avec des données ethnographiques, des interprétations de nature cérémonielle avec des dépôts associés à des rites de passage ou bien funéraires selon qu'il s'agit de vases retournés ou de fosses allongées. Ainsi chez les Wayana, le placenta des nouveau-nés est enterré dans une petite fosse (Hurault 1968, p. 54), creusée à peu de distance de la maison, mais qui peut, lors d'un accouchement pendant la nuit, se faire juste à côté d'un poteau de la maison (Chapuis 1998, p. 309). On soulignera 


\section{Nouveaux apports sur l'archéologie du littoral de Guyane}
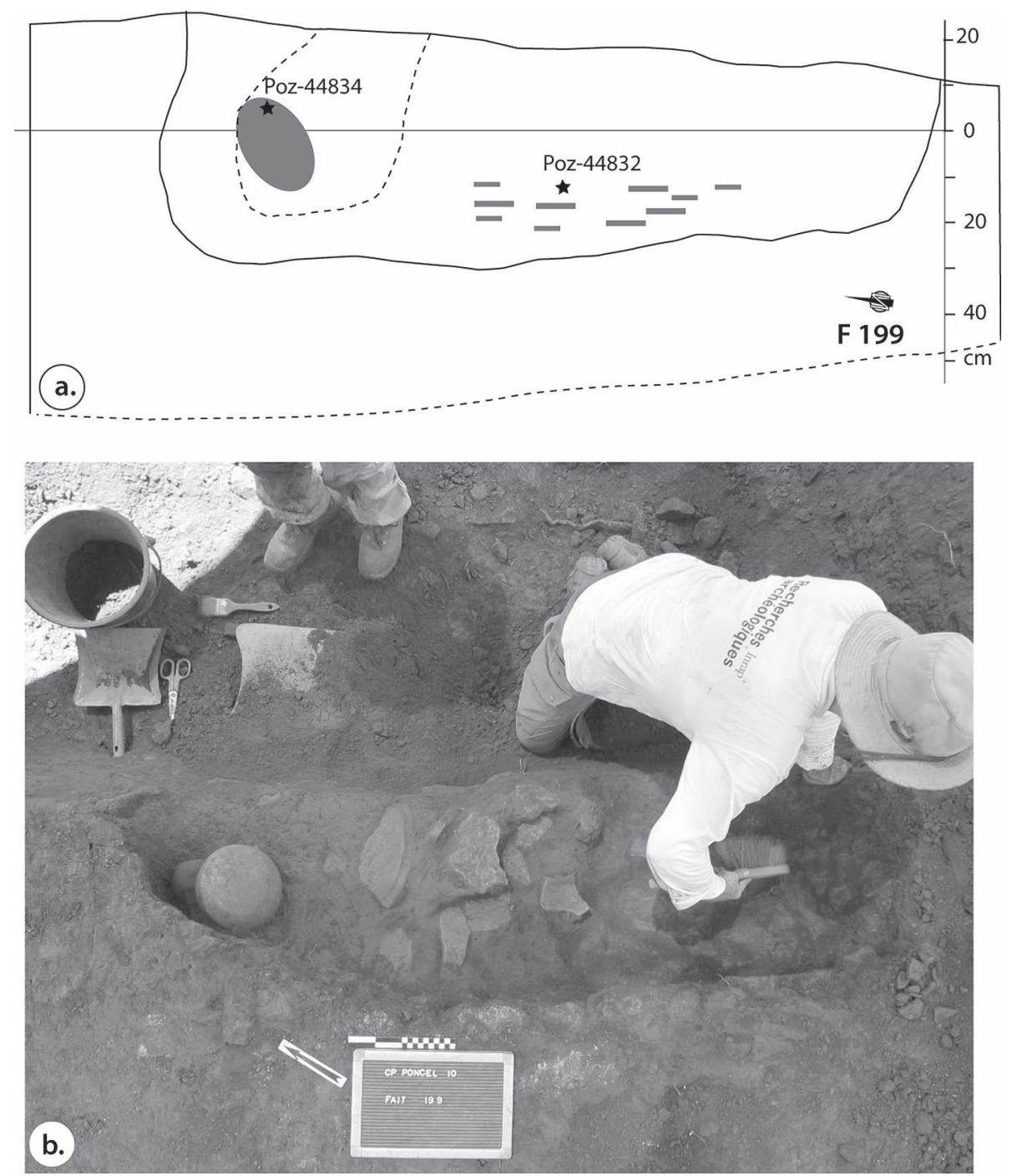

Fig. 10 - Une fosse allongée au Cimetière paysager de Poncel:

a. dessin de la coupe et b. fouille de la fosse (dessin et photo par M. van den Bel). 
que ces comparaisons ne sont évidemment que des pistes d'interprétation ayant pour but d'avancer des hypothèses. Au final, on retiendra malgré tout que les fosses allongées seraient plutôt des fosses sépulcrales (primaires ou secondaires), du fait de leur forme rectangulaire ainsi que du dépôt de céramiques, les corps complets ou certains ossements (dans le cas des enterrements secondaires) n'ayant pas laissé de traces.

La céramique

La céramique des deux sites partage un grand nombre d'éléments caractéristiques de la période récente. Au-delà d'une chaîne opératoire à base de colombins à partir d'une pâte à chamotte et incluant une cuisson réductrice, la céramique se caractérise par cinq modes morphologiques et décoratifs récurrents. Le rattachement de ces céramiques au complexe céramique de Thémire longtemps admis (Rostain 1994b, p. 446-447 ; 2008, p. 293) pose toutefois problème sur les plans chronologique et culturel.

On doit d'abord observer que les quatre types de Thémire, tels qu'ils ont été décrits, présentent une forte hétérogénéité au niveau des formes et des décors. Cette hétérogénéité pourrait être liée à l'utilisation de la méthode " type-variété » (ou « Ford ») pour le classement du matériel, mais aussi à la relativement faible quantité des spécimens dans la base de données ${ }^{14}$. On remarquera aussi que l'omniprésence de la chamotte dans le type Cayenne Peint va de pair avec des formes peintes et que les formes du type Mahury incisé, ayant un dégraissant sableux, sont quant à elles majoritairement pourvues d'incisions. Les résultats de notre propre étude, mais aussi d'autres études faites sur l'île de Cayenne (Hildebrand dans Mestre, Hildebrand et Delpech 2005), démontrent que ces associations supposées pour le complexe Thémire ne s'appliquent pas aussi automatiquement sur les sites de CPP et du Rorota. En fait, les critères principaux du type Cayenne peint (la combinaison d'une pâte à chamotte et d'une peinture rouge) ne concordent pas avec les résultats de CPP où on observe une pâte mixte (chamotte et sable) et un décor incisé. Il faudrait donc s'interroger sur une possible révision de cette typologie cayennaise. À partir d'une approche différente mettant au premier plan la morphologie et au second des décors particuliers, on pourra obtenir une collection de référence des formes les plus populaires (Figure 11).

Concernant les datations ${ }^{14} \mathrm{C}$ des sites attribués à Thémire $(\mathrm{N}=5)$, on remarque qu'elles se situent à la fin de l'époque précolombienne, voire à l'Âge historique (Rostain 1994a, annexe II). Ces dates récentes correspondent plutôt à la dernière

14. Sur le plan méthodologique, Rostain n'avait pas tenu compte des travaux précédents d'Alain Cornette (1990) qui avait appliqué les méthodes descriptives d'Hélène Balfet. Il admet toutefois qu' " il sera nécessaire dans le futur de distinguer de nouveaux types et de subdiviser certains de ceux qui existent en plusieurs variétés » (Rostain 1994a, p. 41, note 2). 


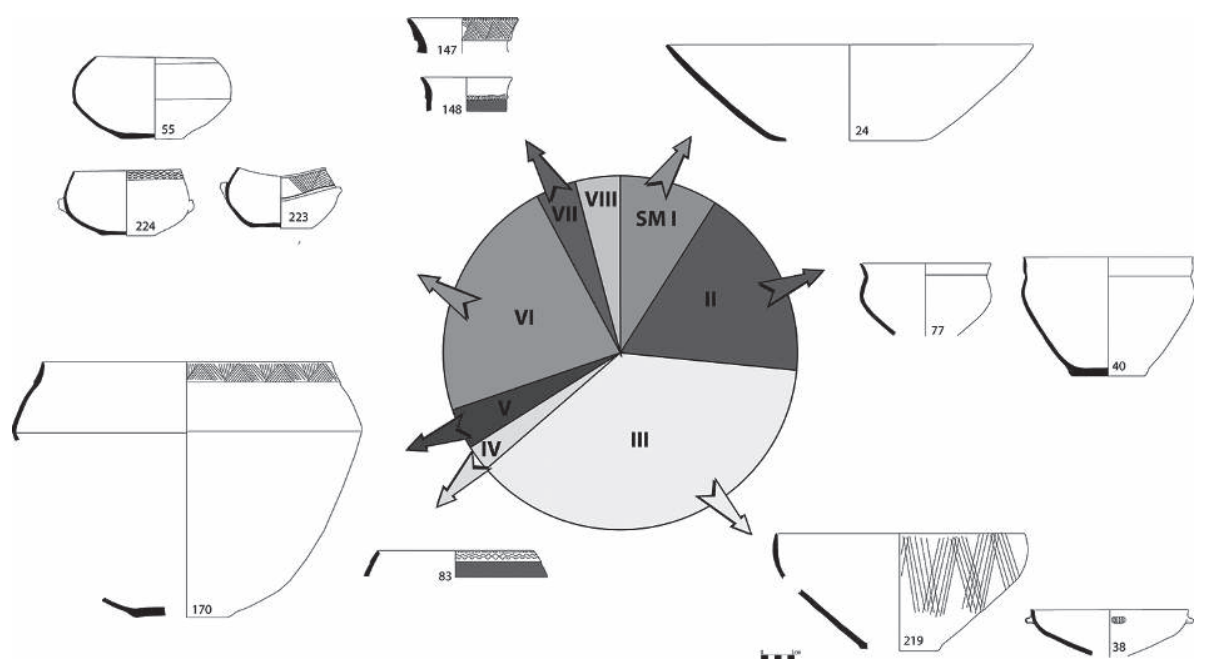

Fig. 11 - Répartition des séries modales céramiques du site

Cimetière paysager de Poncel (schéma par M. van den Bel).

phase d'occupation de CPP, avec les dépôts de vases entiers en forme de cloche ayant un aplat blanc et des dessins complexes en rouge par-dessus (Figure 12, voir page suivante).

Il s'agit certainement d'influences polychromes venant de l'est (Aristé), ainsi que l'a reconnu depuis longtemps Rostain pour la phase finale de Thémire (Rostain 1994a, p. 30 ; 2012a, p. 17 ; 2016, p. 64) ${ }^{15}$. Mais un lien avec le Koriabo est aussi envisageable si l'on tient compte de l'engobe blanc et des formes qui sont partagées par chacun des derniers complexes (Cabral 2011 ; van den Bel 2014 ; Saldanha et al. 2016). Cependant, la relation entre le Koriabo et l'Aristé exigera plus d'attention à l'avenir dans les Guyanes orientales (Saldanha et Cabral 2016), en s'appuyant pour la Guyane notamment sur les résultats des fouilles préventives du site de la Pointe Morne sur l'Oyapock où le Koriabo s'impose à l'Aristé vers 1400 apr. J.-C. (Mestre et Hildebrand 2011) ou encore les fouilles de Sainte-Agathe à Macouria menées par Hildebrand.

En tout cas, les formes et les décors particuliers, que l'on trouve dans les fosses allongées et d'autres structures sur les sites Rorota et CPP, précèdent l'arrivée des polychromes et demeurent donc hors du cadre chrono-culturel proposé jusqu'ici: il s'agit en fait d'un complexe céramique distinct qui précède le Thémire sur l'île de Cayenne et que l'on propose, pour cette raison, de dénommer «Thémire ancien ». Par voie de conséquence, le Thémire original

15. La présence de râpes en céramique sur le mont couronné de Paramana, situé sur l'île de Cayenne, confirme clairement cette présence Aristé tardif (van den Bel 2012a). 
Martijn M. VAN DEN BEL
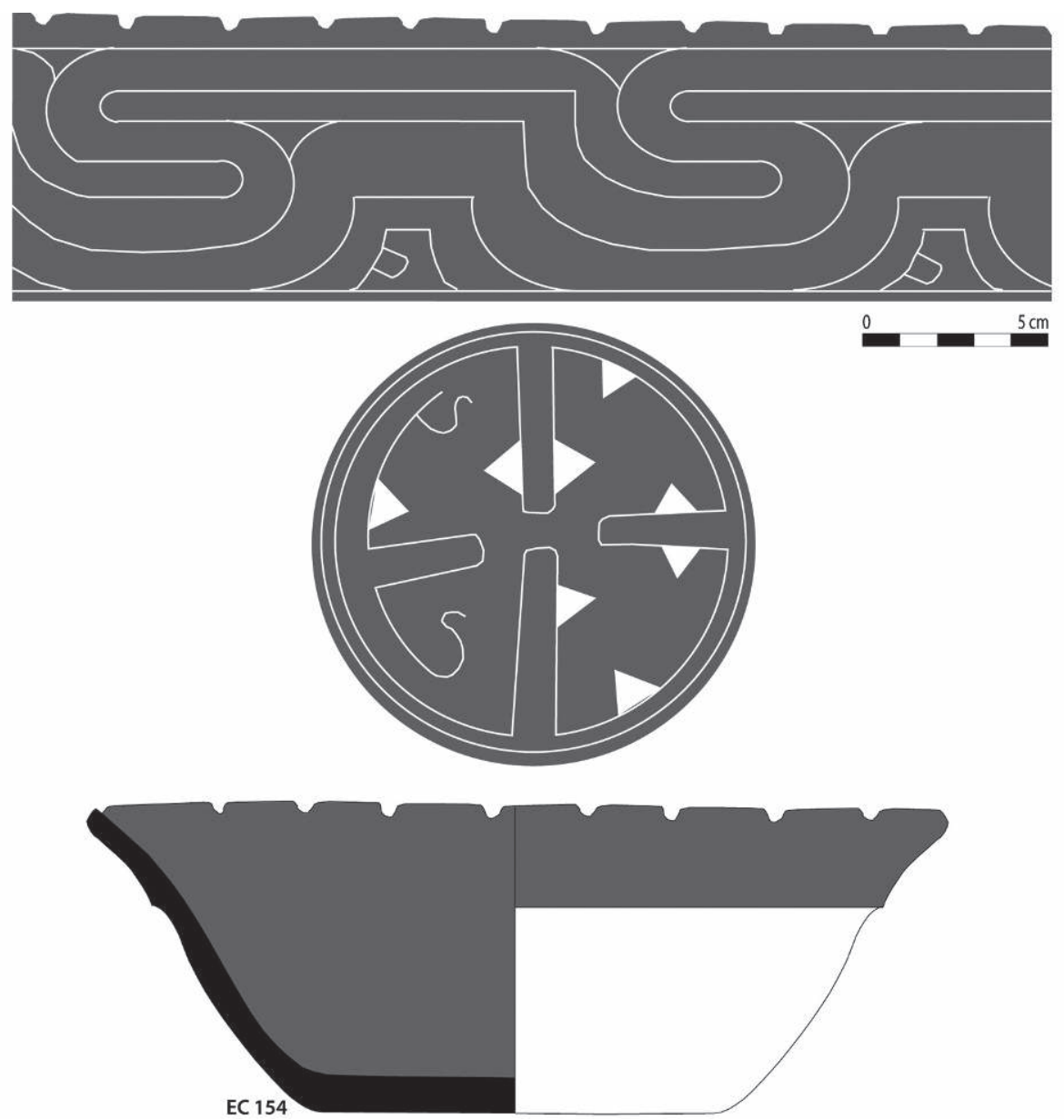

Fig. 12 - Représentation d'un dessin blanc sur rouge à

l'intérieur d'une écuelle trouvé dans la fosse F 93 au Cimetière paysager de Poncel (dessin par M. van den Bel).

sera renommé « Thémire récent ». Les origines du complexe ancien et ses modes d'enterrement, qui représente en réalité localement le début de l'Âge céramique récent, sont pour l'heure encore inconnues. Les formes et les séries qu'on y observe ne partagent aucun élément pertinent avec le complexe Barbakoeba situé plus à l'ouest. Ces séries ne peuvent pas davantage être attribuées à une migration arauquinö̈de depuis le Suriname, n'ayant évidemment rien à voir avec l'ultime diffusion de cette tradition, qui se manifeste vers 1300 apr. J.-C. environ sur l'île de Cayenne, comme l'avait évoqué Hildebrand il y a presque 20 ans (Hildebrand 1999). 
Pour conclure, les nouvelles datations ${ }^{14} \mathrm{C}$ qui ont été obtenues et les données céramiques des sites Rorota et CPP imposent de réviser la typo-chronologie de l'île de Cayenne, en l'occurrence le complexe de Thémire. Il a dû en effet exister une phase ancienne d'origine encore indéterminée, suivie d'une phase tardive, ce qui précise la définition du complexe Thémire, le complexe Koriabo ayant joué un rôle en connexion avec le premier sur le littoral de Guyane.

Le maïs et le manioc

Une dizaine d'artefacts (meules en pierre et fragments de céramique dont des plaques à cuire) issus des deux sites a été analysée afin de déterminer les plantes consommées (van den Bel et al. 2013 ; van den Bel, Pagán Jiménez et Fronteau 2014). L'omniprésence du maïs est flagrante, notamment sur les plaques en céramique, des objets historiquement et actuellement intimement liés à production de la cassave (manioc). Bien que ces données n'apportent pas de réponses définitives quant à la fabrication des produits consommés, elles permettent de s'interroger sur l'importance du manioc et du maïs au sein des populations précolombiennes tardives et historiques (Figure 13). À l'heure actuelle, la base de l'alimentation principale des Amérindiens des Guyanes est indéniablement le manioc amer sous toutes ses formes. On peut constater que le maïs, clairement identifié par les premiers Européens et par les analyses effectuées sur des objets archéologiques, aurait perdu de son importance en faveur du manioc principalement au sein des populations historiques (Iriarte et al. 2012 ; van den Bel 2015a). On notera d'ailleurs qu'un changement similaire a été détecté aux Antilles (Mickleburgh et Pagán Jiménez 2012 ; Figueredo 2015).

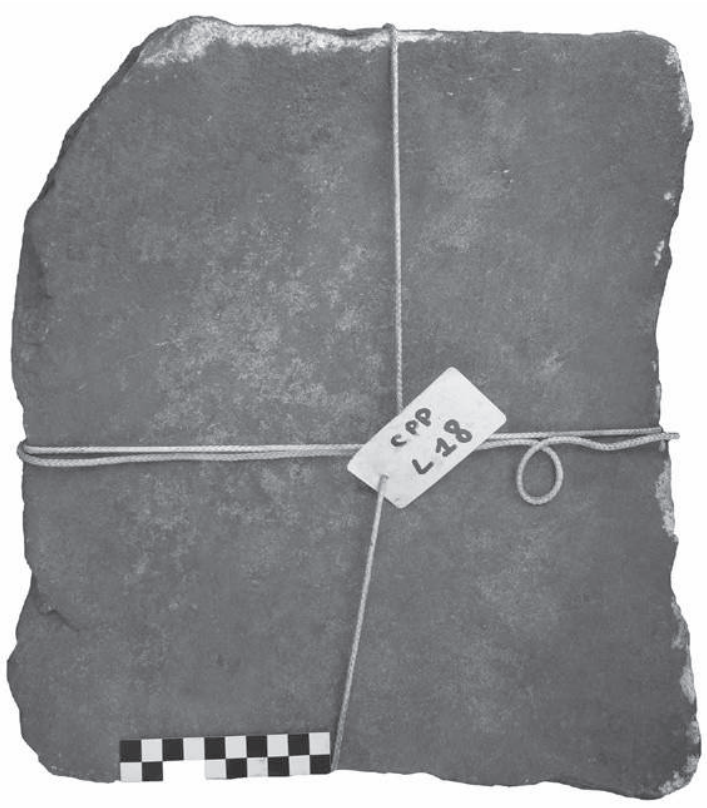

Fig. 13 - Meule utilisé strictement pour le broyage de grains de maïs, trouvé au carré L18 sur le site Cimetière paysager de Poncel (photo par M. van den Bel).

\section{Conclusion}

Les données archéologiques exposées dans ces pages, pour la plupart inédites, permettent de proposer une nouvelle séquence enrichie de l'histoire 
précolombienne en Guyane française à partir des données recueillies depuis une vingtaine d'années. On a pu ainsi démontrer l'existence de périodes anciennes (à Eva 2, CSL, CPP), auparavant seulement soupçonnées, qui permettent de dresser un premier cadre chrono-culturel pour l'Âge céramique ancien et l'Âge archaïque (Figure 14). Quant au cadre chrono-culturel concernant l'Âge céramique récent, il peut être sérieusement précisé à partir des résultats des fouilles de CSL, Sparouine, LPB, SBE et de l'île de Cayenne (CPP et Rorota). *

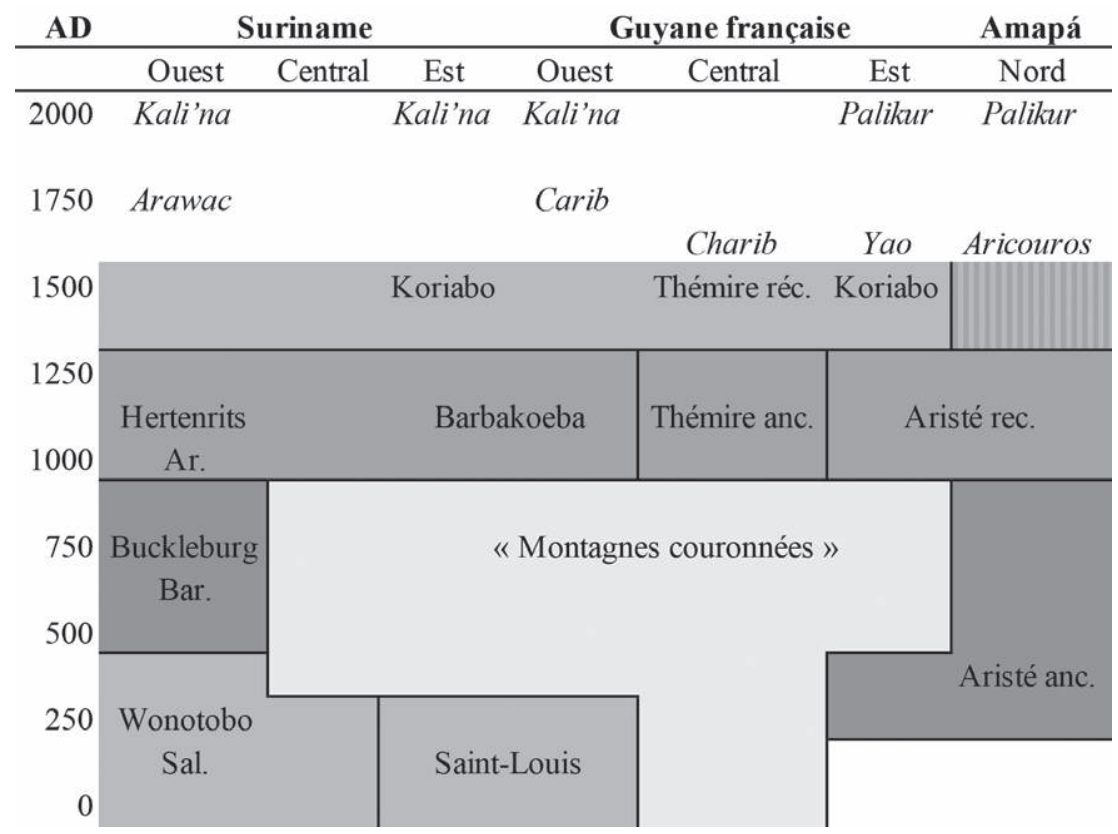

Fig. 14 - Schéma chronoculturel pour la bande littorale du Suriname, Guyane française et la partie septentrionale de l'Amapá des deux derniers millénaires (schéma par M. van den Bel).

* Manuscrit reçu en avril 2017, accepté pour publication en février 2018.

\section{Références citées}

Barrone-Visigalli Egle et Marie-Thérese Prost

1991 Modalités d'occupation des sites amérindiens en Guyane: le cas de la Sablière, à Kourou, rapport de fouilles, Direction des Antiquités/Afan, Cayenne-Pessac, ms.

BEL Martijn VAN DEN

1995 Kamuyune: The Palikur potters of French Guiana, mémoire de Master 2, archéologie et histoire des cultures de l'Amérique amérindienne, université de Leiden, ms. 
2006 Parcelle Am 43 à Iracoubo, Sable Blanc Est, Commune d'Iracoubo, rapport de diagnostic, Inrap, Pessac, ms.

2007 Crique Sparouine: un site amérindien de hauteur dans l'arrière-pays du Bas Maroni, Saint Laurent du Maroni Guyane française, rapport de fouille, Inrap, Pessac, ms.

2009 «Les dépôts funéraires d'Iracoubo : les résultats d'une fouille préventive d'une nécropole précolombienne de Guyane française ", Revista Amazônica, 1 (1), p. 30-49.

2010a «A Koriabo site on the Lower Maroni River: results of the preventive archaeological excavation at Crique Sparouine, French-Guiana », in Edithe Pereira, Vera Guapindaia (dir.), Arquéologia Amazônica 1, MPEG/IPHAN/SECULT, Belém, p. 61-93.

2010 b « Late Archaic cooking pits in coastal French-Guiana, results of a preventive archaeological excavation at the junction of the coastal Pleistocene savannahs and the Precambrian shield », Revista do Arquéologia, 23 (1), p. 60-71.

2010c «Grès rhénan dans une tombe guyanaise ", Archéopages, 28, p. 98-99.

2012a Crique Anguille, Matoury (DOM Guyane), rapport d'opération diagnostic archéologique, Inrap, Bègles, ms.

2012b «Archaeological investigations at the Saint-Louis site on the Lower Maroni River: the ceramic series », Archaeology and Anthropology, Journal of the Walter Roth Museum of Anthropology, 17 (2), p. 1-52.

2014 "Excavations at Poncel: an update of the Late Ceramic Age of Cayenne ", in Stéphen Rostain (éd.), Antes de Orellana. Actas del 3er Encuentro Internacional de Arquéologia Amazônia, IFEA (Actes et Mémoires de l'Institut français d'études Andines, 37), Quito, p. 75-88.

2015a «Uma nota sobre a introdução de raladores de metal e sobre a produção e consumo da mandioca e do milho na zona costeira das Guianas, durante o século XVII », Revista Amazônica, 7 (1), p. 100-132.

2015b Archaeological investigations between Cayenne Island and the Maroni River: a cultural sequence of western coastal French Guiana from 5000 BP to present, thèse de Doctorat, archéologie, université de Leiden, Sidestone Press, Leiden.

2015c «Un cimetière précolombien sur la côte », in Stéphen Rostain (dir.), Archéologie de l'Amazonie. Les premiers habitants de la Guyane côtière, Archaeopress (BAR International Series, 2758 ; Paris Monographs in American Archaeology, 44), Oxford, p. 91-99.

2015d «Rituais funerários e deposição cerâmica nos sítios AM 41 e La Pointe de Balaté: repensando o período cerâmico tardio na planície costeira oeste da Guiana Francesa », Boletim do Museu Paraense Emílio Goeldi, Ciêncas Humanas, 10 (1), p. 11-45.

Bel Martijn van den, Matthieu Hildebrand, Sandrine Delpech, Thomas Romon et Christian VALLET

2006 Les occupations amérindiennes du site Eva 2, Chantier Soyouz du CSG, Malmanoury. Commune de Sinnamary, Guyane Française, rapport de fouille, Inrap, Pessac, ms. 
Martijn M. vAN DEN BEL

Bel Martijn van den, Nathalie Serrand, Laurent Bruxelles, Pascal Verdin, Jaime Pagán Jiménez, Jeanne Brancier, Cécilia Cammas, Jago Birk, Bruno Glazer et Sebastiaan KNIPPENBERG

2011 Chemin Saint-Louis, rapport de fouille, Inrap, Bègles, ms (révisé en octobre 2012), 2 vol.

Bel Martijn van den, Sandrine Delpech, Gilles Fronteau, Jaime Pagán Jiménez et Dominique Todisco

2012 «Le retour au Rorota ». Site néoindien récent sur le littoral de l'île de Cayenne, rapport d'opération de fouille archéologique, Inrap, Bègles, ms.

Bel Martijn van den, Sandrine Delpech, Gilles Fronteau, Jaime Pagán Jiménez et Dominique Todisco

2013 Cimetière paysager Poncel. Le morne Poncel. Un site néoindien récent dans l'arrière-pays marécageux de l'île de Cayenne, rapport d'opération de fouille archéologique, Inrap, Bègles, ms.

Bel Martijn van den, Jaime Pagán Jiménez et Gilles Fronteau

2014 «Le Rorota revisité : résultats des fouilles préventives à PK11, route des Plages, Île de Cayenne (Guyane française) », in Benoît Bérard et Catherine Losier (dir.), Archéologie caraïbe, Sidestone Press (Taboui 2), Leiden, p. 37-76.

Bel Martijn van den, Thomas Romon, Christian Vallet et Sandrine Delpech

2015 «Un village "galibi" en Guyane française ; le cas du site archéologique d'Eva $2 »$, Recherches amérindiennes au Québec, 44 (2-3), p. 127-141.

Bel Martijn van den, Sebastiaan KnipPenberg et Jaime PAgÁn Jiménez

2018 «From cooking pits to cooking pots: changing modes of food processing during the Late Archaic Age in French Guiana », in Basil Reid (dir.), The Archaeology of the Caribbean and Circum-Caribbean Farmers (6000 BC-AD 1500), Routledge, London, p. 391-418.

BoER Martin DE

1972 Landforms and soils in eastern Surinam (South America), thèse de Doctorat, département d'agriculture, École d'hautes études de Wageningen [1971]; Department of Tropical Soil Science (Wageningen Agricultural Research Rapports, 771), Wageningen.

Boomert Arie

1986 «The Cayo Complex of Saint-Vincent: ethnohistorical and archaeological aspects of the Island Carib problem », Antropológica, 66, p. 3-68.

1993 « The Barbakoeba Archaeological Complex of Northeast Surinam », OSO Tijdschrift voor Surinamistiek, 12 (2), p. 98-222.

2000 Trinidad, Tobago and the Lower Orinoco Interaction Sphere, An archaeological/ethnohistorical study, thèse de Doctorat, archéologie, université de Leiden, Cairi Publications, Alkmaar.

2004 « Koriabo and the polychrome tradition: the Late-Prehistoric era between the Orinoco and Amazon mouths », in André Delpuech et Corinne Hofman (dir.), Late Ceramic Age Societies in the Eastern Caribbean, Archaeopress (BAR 
International Series, 1273 ; Paris Monographs in American Archaeology, 14), London, p. 251-266.

BRANCIER Jeanne

2009 Géoarchéologie des terres noires guyanaises: approche bibliographique et premières données analytiques sur le site de Chemin Saint-Louis (SaintLaurent-du-Maroni, Guyane française), mémoire de Master 2, archéologie et environnement, université Paris 1 Panthéon-Sorbonne, 2 vol., ms.

Brancier Jeanne, Cécilia Cammas, Dominique Todisco et Eric Fouache

2014 «A micromorphological assessment of Anthropogenic features in PreColumbian French Guiana dark soils (FGDS): first results », Zeitschrift für Geomorphologie, Supplementary Issue, 58 (2), p. 109-139, https://doi. org/10.1127/0372-8854/2014/S-00159, consulté le 13/12/18.

BRIAND Jérôme

2015 Carrière Luna (S2), Projet Ariane 6-CSG, Kourou, Guyane, rapport de diagnostic, Inrap, Bègles, ms.

Briand Jérôme, Jeanne Brancier, Sandrine Delpech, Pierre-Yves Villiers, Anne-Marie Faucher, Christine Foullloud, Olivier OnÉzime, Thomas Romon, Dominique Todisco, Martijn VAN den Bel et Pascal Verdin

2016 Pointe Balaté, Saint-Laurent-du-Maroni, Guyane, DOM, rapport de fouille, Inrap, Bègles, ms.

BrinKMAn Ronald et Leendert J. Pons

1968 A pedo-geomorphological classification and map of the Holocene sediments in the coastal plain of the three Guianas, Netherlands Soil Survey Institute (Soil survey papers, 4), Wageningen.

Bush Mark, Miles Silman, Crystal McMichael et Sassan SaAtchi

2008 «Fire, climate change and biodiversity in Amazonia Late-Holocene perspective », Philosophical Transactions of the Royal Society B: Biological Sciences, 363, p. 1795-1802.

CABral Mariana Petry

2011 « Juntando cacos: uma reflexão sobre a classificação da fase Koriabo no Amapá », Amazônica, 3, p. 88-106.

ChApuIs Jean

1998 La personne wayana entre sang et ciel, thèse de Doctorat, anthropologie, université d'Aix-Marseille ; Presses universitaires du Septentrion, Lille, 2000.

Choubert Boris, Jacques Barruol, Pierre Coudert, René Leenhardt et M. Robert

1958 Feuille 4B de Kourou, carte géologique détaillée de la France, département de la Guyane à l'échelle du 1/100 000, ministère de l'Industrie et du Commerce, Paris.

Clemente-Conte Ignacio, Eric BoëDa et Maria Faria-Gluchy

2016 «Macro- and micro-traces of hafting on quartz tools from Pleistocene sites in the Sierra de Capivara in Piaui (Brazil) », Quaternary International, 427, p. 206-210. 
Martijn M. vAN DEN BEL

CORnETTE Alain

1985 Site archéologique de Crique Jacques (Mana, Guyane). Deuxième rapport, Mission AGAE du 9 à 14 septembre 1985, rapport de mission archéologique, Direction des Antiquités/AGAE, Cayenne, ms.

1990 «La céramique amérindienne de Guyane », in Agamemnon Gus Pantel Tekakis, Iraida Vargas Arenas et Mario Sanoja Obediente (dir.), Proceedings of the 11th Congress of the international association for Caribbean Archaeology at Puerto Rico 1985, Foundation of Archaeology, Anthropology and History of Puerto Rico, p. 196-213.

CORRÊA Conceição et Mario SIMÕES

1971 «Pesquisas arquelogicas nas regiao do Salgado. A fase Areão do litoral de Marapanim », Boletim do Museu Paraense Emílio Goeldi, Nova Série Antropologia, 48, p. 1-30.

Coutet Claude

2011 [2009] Archéologie du Littoral de Guyane française. Une approche ethnoarchéologique des techniques céramiques amérindiennes, thèse de Doctorat, archéologie, université Paris I Panthéon-Sorbonne ; Presses universitaires Européennes, Paris.

Coutet Claude, Thomas Romon et Nathalie SerRand

2014 «Ossements et perles en coquillage des sépultures précolombiennes de Yalimapo (Awala-Yalimapo) », Karapa, 3, p. 21-34.

CRuXent José Maria

1971 «Apuntes sobre arquelogia Venezolana », in José Maria Cruxent et Sagrario Pérez Soto de Atencio Mendoza (dir.), Arte Prehispanico de Venezuela, Fundación Eugenio Mendoza, Caracas, p. 18-59.

1972 « Tupuquén: un yacimiento con lítica de tipo Paleo-Indio », Acta Científica Venezolana, 23 (1), p. 17.

DeLPECH Sandrine

2010 Chennebras - Avenue de Saint-Cyr, Rémire-Montjoly, Guyane, Dom-Tom, rapport final d'opération de diagnostic archéologique, Inrap, Bègles, ms.

2015 «Rites funéraires de l'Île de Cayenne: l'exemple du site de Mombin II, Rémire-Montjoly », Karapa, 4, p. 8-19.

2017 Mombin II, Route de Rémire, Rémire-Montjoly, Guyane, DROM, rapport d'opération de fouille archéologique, Inrap, Bègles, ms.

Dering Phil

1999 «Earth-oven plant processing in Archaic Period economies: an example from a semiarid savannah in South-Central North America », American Antiquity, 64 (4), p. 659-674.

Evans Clifford et Betty MegGers

1960 Archaeological investigations in British Guiana, Smithsonian Institution (Bulletin Bureau of American Ethnology, 177), Washington (DC). 


\section{FigUEREDO Alfredo}

2015 «Manioc dethroned and maize triumphant. Interpretations on the Ethnohistory and Archaeology of the Bahamas (with Sundry notes on relations of production) », paper presented at the Society for American Archaeology 77th Annual Meeting [18-22 April, 2012, Memphis (Tennessee)], publié posthumus dans Journal of Caribbean Archaeology, 15, p. 120-134

Gassies Eric et Georges Lemaire

2006 Rapport d'intervention, DRAC Guyane/SRA, Cayenne, ms.

GoEJE Claudius DE

1943 «Neolitische Indianen in Suriname (met gegevens der expeditie-Ahlbrinck 1938 », Tijdschrift van het Nederlandsch Aardrijkskundig Genootschap, 60 (3), p. 334-374.

Grouard Sandrine, Jérôme Briand, Nicolas Federoff, Marc JARRY et Christophe TARdy 1997 Un site d'habitat de hauteur amérindien précolombien sur l'Ile de Cayenne. Mont Grand-Matoury, 97307.008 (Guyane française), DFS de fouille préventive AFAN/SRA, Pessar/Cayenne, ms.

Guapindaia Vera

2001 «Encountering the ancestors: the Maracá urns », in Colin McEwan, Cristiana Barreto et Eduardo Góes Neves (dir.), Unknown Amazon. Culture and nature in Ancient Brazil, British Museum Press, London, p. 156-173.

HildeBrand Matthieu

1999 L'ensemble arauquinö̈de: tradition ou complexe culturel? Essai d'analyse d'un ensemble culturel de la zone Orénoquo-guyanaise, DEA, archéologie, université Paris I Panthéon-Sorbonne, ms.

2008 Saut-Saillat: une occupation diachronique de Berge Haute, Saint-Laurent du Maroni (Guyane française), rapport de fouille, Inrap, Bègles, ms.

HuRAult Jean-Marcel

1968 Les Indiens Wayana de la Guyane française: structure sociale et coutume familiale, Éditions ORSTOM, Paris.

1989 Français et Indiens en Guyane 1604-1972, Guyane Press Diffusion, Cayenne, [2 éd.].

Iriarte José, Mitchell Power, Stéphen Rostain, Frank Mayle, Huw Jones, Jennifer Watling, Bronwen Whitney et Doyle McKey

2012 «Fire-free land use in pre-1492 Amazonian savannas », Proceedings of the United States National Academy of Science, 109 (17), p. 6473-6478, www. pnas.org/cgi/doi/10.1073/pnas.1201461109, consulté le 13/12/18.

Issenmann Régis, Sylvie BARrier, Sébastien Gomez et Lolita Rousseau

2018 Macouria «Les Roches Rouges », Périphérie d'un habitat amérindien. Rapport final d'opération archéologique (fouille préventive) Éveha - Études et valorisations archéologiques, Limoges, ms. 
Martijn M. vAN DEN BEL

JÉrÉmie Sylvie, Mickaël Mestre et Nathalie CAzelles

2002 Lotissement Katoury, $n^{\circ}$ opération: 2002-23-0001, site 97302078, commune de Cayenne (97302), rapport de diagnostic, Inrap, Pessac, ms.

KNIPPENBERG Sebastiaan

2012 «Archaeological investigations at the Saint-Louis on the Lower Maroni River: the Lithic Study », Journal of the Walter Roth Museum of Archaeology and Anthropology, 17 (2), p. 53-77.

McKey Doyle, Stéphen Rostain, José Iriarte, Bruno Glaser, Jago Birk, Irene Holst et Delphine RENARD

2010 «Pre-Columbian agricultural landscapes, ecosystem engineers, and selforganized patchiness in Amazonia ", Proceedings of the National Academy of Sciences, 107 (17), p. 7823-7828.

McKey Doyle, Mélisse Ducreu, Axelle Solibieda, Christine Raimond, Kisay Adame Montoya, José Iriarte, Delphine Renard, Serena Suarez Jimenez, Stéphen Rostain et Anne ZangerLe

2014 «New approaches to pre-Columbian raised-field agriculture: ecology of seasonally flooded savannas, and living raised fields in Africa, as windows on the past and the futures », in Stéphen Rostain (éd.), Amazonía. Memorias de las Conferencias Magistrales del 3er Encuentro Internacional de Arqueología Amazónica, EIAA/IKIAM/SNESCTI, Quito, p. 91-136.

Marques Arkley BandeIRA

2009 «Pesquisa Arqueológica no sambaqui do Bacanga, São Luís, Maranhão: reflexões sobre a ocorrência de cerâmica em sambaquis do litoral equatorial amazônico », Revista Amazônica, 1 (2), p. 484-511.

Mayle Frank et Mitchell Power

2008 «Impact of a drier Early Mid-Holocene climate upon Amazonian forests », Philosophical Transactions of the Royal Society B: Biological Sciences, 363 (1498), p. 1829-1838.

MAZIÈRE Guy

1996 «Montagne Favard, Régina-Kaw », Bilan Scientifique de la Région Guyane 1996, p. 30-33.

Mestre Mickaël

2008 Saint-Laurent-du-Maroni. Les Hauts de Balaté (Guyane française), rapport de diagnostic, Inrap, Pessac, ms.

Mestre Mickaël et Sandrine Delpech

2008 Saint-Laurent du Maroni. Plateau des Mines, rapport de fouille, Inrap, Pessac, ms.

Mestre Mickaël et Matthieu Hildebrand

2011 «Pointe Morne: la rencontre de deux mondes amérindiens », in Gérald Migeon (dir.), Un Pont sur l'Oyapock, Guide de l'exposition, MEEDT/DRAC/ DEAL, Cayenne, p. 10-13. 
Nouveaux apports sur l'archéologie du littoral de Guyane

Mestre Mickaël, Matthieu Hildebrand et Sandrine DelPech

2005 Katoury, Cayenne, Guyane française, rapport final de fouille, Inrap, Pessac, ms.

Mickleburgh Hayley et Jaime Pagán JiméneZ

2012 «New insights into the consumption of maize and other food plants in the preColumbian Caribbean from starch grains trapped in human dental calculus », Journal of Archaeological Science, 39, p. 2468-2478.

Nieuwenhuis Channah

2002 Traces on tropical tools. A functional study of chert artefacts from preceramic sites in Colombia, thèse de Doctorat, archéologie, université de Leiden ; Leiden University Press (Archaeological Studies Leiden University, 9), Leiden.

Nimuendajú Curt

1926 « Die Palikur-Indianer und ihre Nachbarn », Göteborgs Kungl. Vetenskapsoch Vitterhets-Samhälles Handlingar, 31 (2).

PAGÁn JiMÉNEZ Jaime

2012 «Early use of maize and other food crops among Early Ceramic and later Neoindian traditions of northeastern Amazonia revealed by ancient starch grains from ceramic and lithic artefacts of the Chemin Saint-Louis archaeological site, French Guiana », Journal of the Walther Roth Museum of Archaeology and Anthropology, 17 (2), p. 78-107.

Pagán Jiménez Jaime, Reniel Rodriguez-Ramos, Basil Reid, Martijn van Den BeL, Corinne HoFman

2015 «Early maize dispersal into the Southern Caribbean and Northeastern South America », Quaternary Science Review, 123, p. 231-246.

Palvadeau Eric

1999 Géodynamique quaternaire de la Guyane française, thèse de Doctorat, géosciences, université de Bretagne Occidentale ; Éditions BRGM (Documents du BRGM, 287), Orléans.

Petitjean Roget Hugues

1983 «Évolution et décadence de l'art funéraire des sites pré et post-colombiens de la baïe de l'Oyapock », in Louis Allaire et Francine Mayer (dir.), Proceedings of the ninth International Congress for the Study of the pre-Columbian Cultures of the Lesser Antilles, Santo Domingo 1981, Centre des recherches caraïbes, Université de Montréal, Montréal, p. 183-200.

Petitjean Roget Hugues et Dominique Roy

1976 « Site archéologique du Rorota, Guyane », in Ripley Bullen (dir.), Proceedings of the 6th Congress of the International Association for Caribbean Archaeology, Pointe-à-Pitre 1975, Société d'histoire de la Guadeloupe et la municipalité de Pointe-à-Pitre, Basse-Terre, p. 165-174.

Prous André, Marcio Alonso, Gustavo Neves de Souza, Angelo Pessoa Lima et Filipe AMORELI

2010 «La place et les caractéristiques du débitage sur enclume ("polaire”) dans les industries brésiliennes », Paléo, numéro spécial 1, p. 201-219. 
Martijn M. vAN DEN BEL

RENARD Delphine

2010 Histoire et écologie des complexes de champs surélevés dans les savanes côtières de Guyane française, thèse de Doctorat, biologie et écologie, université de Montpellier 2, Montpellier, ms.

\section{Roosevelt Anna}

1995 «Early pottery in the Amazon, twenty years of scholarly obscurity », in William Barnett et John Hoopes (dir.), The emergence of pottery, technology and innovation in Ancient Societies, Smithsonian Institution Press, Washington, p. 115-131.

\section{Rostain Stéphen}

1994a «Archéologie du littoral de Guyane. Une région charnière entre les influences culturelles de l'Orénoque et de l'Amazone », Journal de la Société des américanistes, 80, p. 9-46.

1994b L'occupation amérindienne ancienne du littoral de Guyane, thèse de Doctorat, archéologie, université Paris I-Panthéon-Sorbonne ; Éditions de l'ORSTOM (Travaux et Documents Microfiches, 129), Paris, 2 vol.

2008 " Agricultural earthworks on the French Guiana Coast », in Helena Silverman et William Isbell (dir.), Handbook of South American Archaeology, Springer, New York, p. 217-234.

2012a «Where the Amazon River meets the Orinoco River: Archaeology of the Guianas », Revista Amazônica, 4 (1), p. 10-28.

$2012 \mathrm{~b}$ Islands in the rainforest: landscape management in pré-Columbian Amazonia, Michelle Eliott (trad.), Walnut Left Coast Press (New frontiers in historical ecology 4), Walnut Creek.

2015 «Le Projet "Préhistoire de la côte occidentale de Guyane" », in Stéphen Rostain (dir.), Archéologie de l'Amazonie. Les premiers habitants de la Guyane côtière, Archaeopress (BAR International Series, 2758 ; Paris Monographs in American Archaeology, 44), Oxford, p. 13-29.

2016 «La cerámica de la Guyanas », in Cristiana Barreto, Helena Pinto Lima et Carla Jaimes Betancourt (dir.), Cerâmicas arqueológicas da Amazônia: Rumo a uma nova sintese, IPHAN/MPEG, Belém, p. 55-70.

Rostain Stéphen, Nicolas Gentil et Lydie CLerC

2008 Sable Blanc Est, rapport de la fouille programmée, CNRS/Université PanthéonSorbonne, Paris, ms.

Rostain Stéphen, Laure DÉodat et Lydie ClerC

2009 Bois Diable, rapport de campagne de la fouille programmée 2008, CNRS/ Université Panthéon-Sorbonne, Paris, ms.

Rотн Walter E.

1924 An introductory study of the arts, crafts, and customs of the Guiana Indians, Thirty Eighth annual report of the Bureau of American Ethnology to the Secretary of the Smithsonian Institution, United States Government Printing Office, Washington. 
Nouveaux apports sur l'archéologie du littoral de Guyane

Rouse Irving

1972 An introduction to prehistory: a systematic approach, McGraw Hill, New York.

1992 The Tainos. Rise and decline of the people who greeted Columbus, Yale University Press, New Haven.

Rouse Irving et José CRUXENT

1963 Venezuelan Archaeology, Yale University Press, New York.

SAldanha João Darcy et Mariana Petry CABral

2016 «O Estuário do Amazonas revisitado: recentes pesquisas junto ao canal norte », Arquivos do Museu de História Natural e Jardim Botânico, 25 (1), p. 194-235.

Saldanha João Darcy, Mariana Petry Cabral, Alan Da Silva Nazare, Jelly Souza Lima, Michel Bueno Flores Da Silva

2016 « Os complexos cerâmicas do Amapá: proposta de uma nova sitematização », in Cristiana Barreto, Helena Pinto Lima et Carla Jaimes Betancourt (dir.), Cerâmicas arqueológicas da Amazônia: rumo a uma nova síntese, IPHAN/ MPEG, Belém, p. 86-96.

SEGUIN Guillaume

2017 Les Mombins III, Rémire-Montjoly (Guyane). Une aire funéraire du Néoindien récent, rapport final d'opération archéologique (fouille préventive Éveha Études et valorisations archéologiques), Limoges, ms.

SEURIN Maggie

1976 «Étude d'un cordon littoral à l'Anse de Rémire (Guyane) », Connaissance de la Guyane, 3, p. 6-22.

SiMÕEs Mario

1981 «Coletores-pescadores ceramistas do litoral do Salgado (Pará). Nota Preliminar », Boletim do Museu Paraense Emílio Goeldi, Série Antropologia, 78, p. 1-32.

TARDY Christophe

1998 Paleoincendies naturels, feux anthropiques et environnements forestiers de Guyane française du Tardiglaciaire à l'Holocène récent. Approches chronologique et anthracologique, thèse de Doctorat, biologie et écologie, université Montpellier 2, ms.

Thoms Alston

2003 «Cook-stone technology in North America: evolutionary changes in domestic fire structures during the Holocene », in Marie-Chantal Frère-Sautot (dir.), Le Feu domestique et ses structures au Neolithic et aux Âges des Métaux, Éditions Monique Mergoil (Préhistoires 9), Paris, p. 87-96.

2009 « Rocks of Ages: propagation of hot-rock cookery in Western North America », Journal of Archaeological Science, 36 (3), p. 573-591.

THOORIS Catherine

1994 Kourou, La Sablière du Bois Diable, Site amérindien de plein air, report de fouille programmée, SRA/Afan, Cayenne, ms. 
Martijn M. vAN DEN BEL

VACHER Stephane, Sylvie JÉRÉMIE et Jérôme BRIAND

1998 Amérindiens du Sinnamary (Guyane): archéologie en forêt équatoriale, Éditions de la Maison des sciences de l'homme (Document d'archéologie française, 70), Paris.

Versteeg Aad

1980 « $\mathrm{C}^{14}$ dateringen van archeologische vindplaatsen in Suriname », Mededelingen Stichting Surinaams Museum, 32, p. 38-56.

1985 The Prehistory of the young coastal plain of West Suriname, thèse de Doctorat, archéologie, université de Leiden (Berichten van de Rijksdienst voor het Oudheidkundig Bodemonderzoek, 35), Leiden, p. 653-750.

WILLEY Gordon

1971 An Introduction to American Archaeology, vol. 2. South America, Englewood Cliffs Prentice Hall, New Jersey.

Williams Dennis

2003 Prehistoric Guiana, Ian Randle Publishers, Kingston/Miami.

\section{Annexes}

\section{Annexe I - Liste des fouilles archéologiques en Guyane française entre 1975} et $\mathbf{2 0 1 5}$

On doit noter que les fouilles préventives de Roches Savanne (Ouanary), Sainte-Agathe (Macouria), Pointe Morne (Saint-Georges de l'Oyapock), Luna (Kourou) et Perle noire (Rémire-Montjoly), ainsi que les fouilles programmées de Chennebras (Rémire-Monjoly) et Fortunat/Kaipiri ne figurent pas dans ce tableau car les rapports sont non-rendus ou à paraître. 
Nouveaux apports sur l'archéologie du littoral de Guyane

\begin{tabular}{|c|c|c|c|c|c|c|c|c|c|c|c|c|}
\hline 这 & 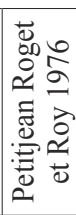 & $\mid \begin{array}{l}0 \\
2 \\
0 \\
0 \\
0 \\
0 \\
0 \\
0\end{array}$ & 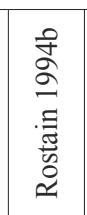 & 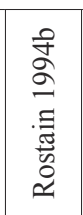 & 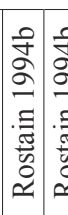 & & 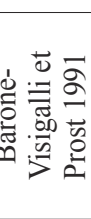 & 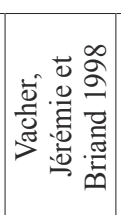 & 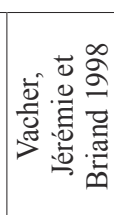 & 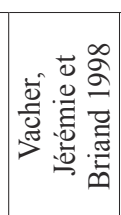 & 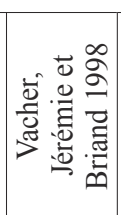 & 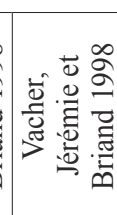 \\
\hline 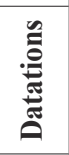 & 0 & 0 & in & $\sim$ & 00 & & $\sim$ & ㄱ. & $\sim$ & m & $r$ & $\stackrel{\sim}{\sim}$ \\
\hline 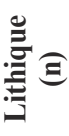 & - & 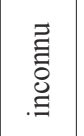 & $\stackrel{\text { 年 }}{\mathrm{N}}$ & 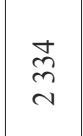 & $\vec{m}$ & & $\underline{m}$ & aे & $\hat{n}$ & $a$ & $\stackrel{\circ}{\circ}$ & $\stackrel{\varrho}{\varrho}$ \\
\hline 苞 & $\stackrel{\infty}{\infty}$ & $\begin{array}{l}\frac{00}{2} \\
\frac{0}{n}\end{array}$ & $\begin{array}{l}n \\
\infty \\
n \\
n\end{array}$ & $\underset{\stackrel{+}{+}}{\stackrel{+}{a}}$ & 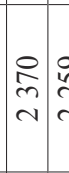 & & 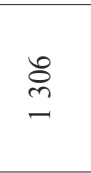 & $\begin{array}{l}n \\
\infty \\
\infty \\
\approx\end{array}$ & $\stackrel{\infty}{\underset{N}{N}}$ & $\begin{array}{l}\infty \\
\stackrel{0}{0} \\
-\end{array}$ & 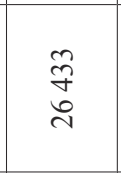 & $\begin{array}{l}\text { t } \\
\text { O } \\
0\end{array}$ \\
\hline 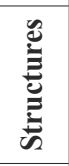 & 0 & 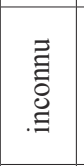 & 0 & - & 0. & - & $m$ & $\stackrel{\Xi}{\Xi}$ & $\cong$ & $\because$ & $\bar{\infty}$ & 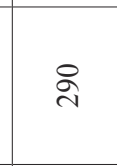 \\
\hline$\Xi$ & - & $\cong$ & $\circ$ & तి & $n 5$ & $\infty$ & $r$ & 吕 & $\begin{array}{l}\stackrel{0}{0} \\
\infty \\
-1\end{array}$ & 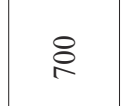 & $\stackrel{\overbrace{}}{\simeq}$ & $\begin{array}{l}0 \\
\infty \\
\infty \\
-1\end{array}$ \\
\hline 营 & $\stackrel{n}{2}$ & $\stackrel{2}{\approx}$ & $\begin{array}{l}\infty \\
\stackrel{\infty}{=}\end{array}$ & $\stackrel{\mathscr{O}}{=}$ & 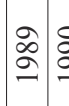 & 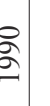 & $\bar{\sigma}$ & $\bar{\sigma}$ & $\bar{\sigma}$ & $\stackrel{\varrho}{\sigma}$ & $\stackrel{2}{\sigma}$ & ڤ్ \\
\hline 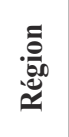 & 莺 & 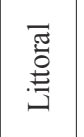 & $\begin{array}{l}\text { 苛 } \\
\text { 总 }\end{array}$ & 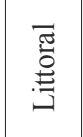 & 要 & 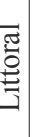 & 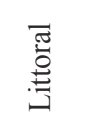 & 离 & : & 离 & 言 & 言 \\
\hline$\stackrel{0}{\stackrel{2}{*}}$ & 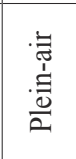 & 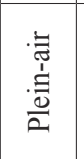 & 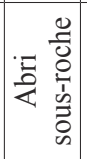 & 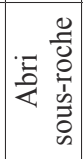 & 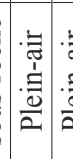 & : & 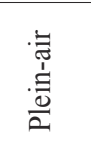 & 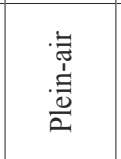 & 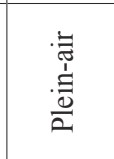 & 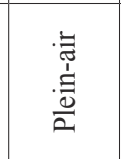 & 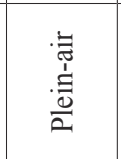 & 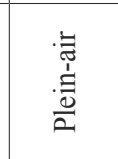 \\
\hline 气 & 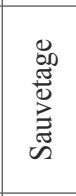 & 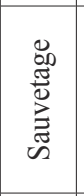 & 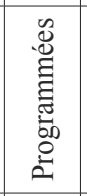 & 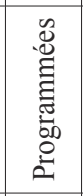 & 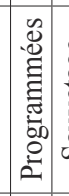 & 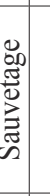 & 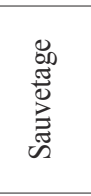 & 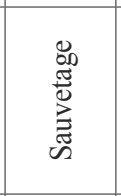 & 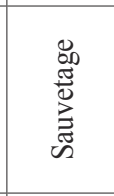 & 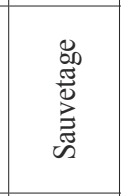 & 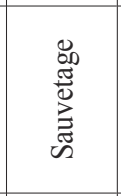 & 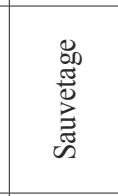 \\
\hline$\stackrel{\Xi}{\circ}$ & 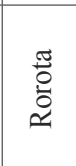 & 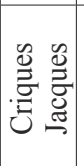 & 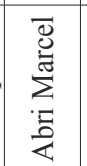 & 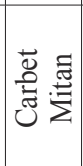 & : & & 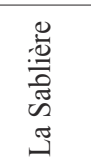 & $\begin{array}{l}m \\
\tilde{n} \\
\hat{n}\end{array}$ & $\begin{array}{l}0 \\
\infty \\
\stackrel{n}{n}\end{array}$ & $\begin{array}{l}\stackrel{\bar{n}}{n} \\
\hat{n}\end{array}$ & $\begin{array}{l}\stackrel{N}{\subseteq} \\
\tilde{n} \\
\stackrel{n}{n}\end{array}$ & $\begin{array}{l}\tilde{N} \\
\tilde{n} \\
\hat{\infty}\end{array}$ \\
\hline
\end{tabular}


Martijn M. van den BeL

\begin{tabular}{|c|c|c|c|c|c|c|c|c|c|c|c|c|}
\hline 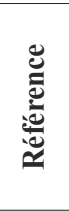 & 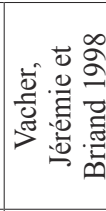 & 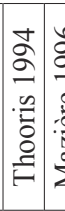 & 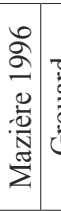 & 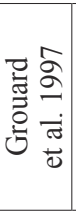 & 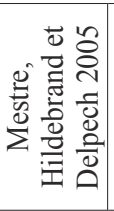 & 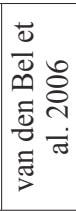 & 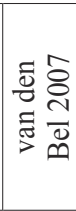 & 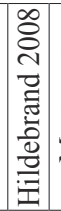 & 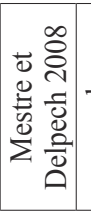 & 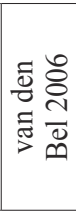 & 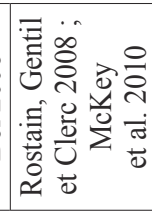 & 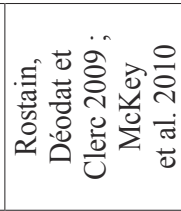 \\
\hline 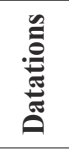 & ㄱ. & 0. & - & $\simeq$ & $\nabla$ & in & $\nabla$ & $\nabla$ & $\infty$ & - & $r$ & - \\
\hline 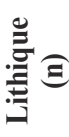 & $\underset{\delta}{0}$ & $\infty$ & \begin{tabular}{|c|}
$\vec{\Xi}$ \\
$\vdots$ \\
0 \\
. \\
.
\end{tabular} & ర్రి & $\underset{f}{\stackrel{f}{f}}$ & $\begin{array}{l}\cong \\
\cong\end{array}$ & $\cong$ & $\vec{\sim}$ & $\begin{array}{l}\text { to } \\
\text { L } \\
气\end{array}$ & $\sim$ & 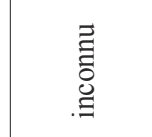 & 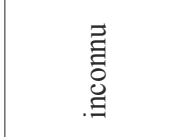 \\
\hline ฮั & $\begin{array}{l}\bar{\delta} \\
\delta\end{array}$ & $\mid$ & 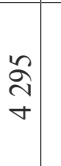 & $\begin{array}{l}\stackrel{8}{7} \\
\dot{7}\end{array}$ & $\begin{array}{l}\tilde{\sigma} \\
\tilde{n} \\
\tilde{n}\end{array}$ & \&̊ & $\underset{n}{\stackrel{2}{2}}$ & $\begin{array}{c}y \\
n \\
n\end{array}$ & 0 & ర్రి & $\begin{array}{l}\text { 䓂 } \\
\text {. }\end{array}$ & 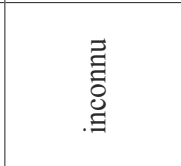 \\
\hline 裳 & 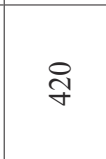 & 0 & 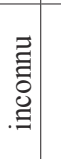 & తి & $\hat{\sigma}$ & $\stackrel{P}{f}$ & $\stackrel{\infty}{\mathscr{f}}$ & ช & $\approx$ & $\Xi$ & $\stackrel{\cong}{=}$ & $\vec{\infty}$ \\
\hline$\cong$ & 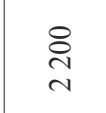 & đ) & $q$ & \&্ণ & $\begin{array}{l}8 \\
0 \\
\vdots\end{array}$ & $\frac{8}{n}$ & $\begin{array}{l}\text { oे } \\
\text { ते }\end{array}$ & $\begin{array}{l}8 \\
0 \\
-2\end{array}$ & $\hat{i}$ & 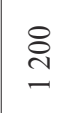 & ల్ల & $\stackrel{\Xi}{=}$ \\
\hline 苋 & $\stackrel{\sigma}{\sigma}$ & $\tilde{\partial}$ & ڤ̊ & $\stackrel{\circ}{\circ}$ & ڤ్ণి & ڤे & ڤ્ণ & 离 & ¿্ণ & ๕ัे & 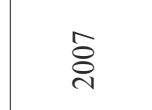 & $\stackrel{\infty}{\stackrel{\sim}{े}}$ \\
\hline 竞 & 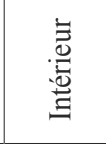 & : & 呇 & 覀 & 莺 & $\begin{array}{l}\text { 苛 } \\
\text { 总 }\end{array}$ & 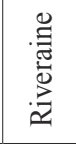 & 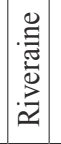 & 离 & 惡 & 覀 & 䔊 \\
\hline 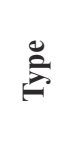 & 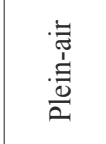 & 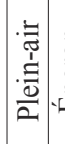 & | & 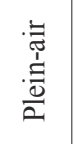 & 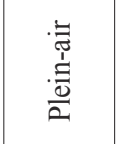 & $\begin{array}{l}\text { 章 } \\
\text { 离 } \\
\frac{\pi}{2}\end{array}$ & $\begin{array}{l}\text { 壱 } \\
\text { 竘 } \\
\frac{\pi}{2}\end{array}$ & 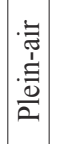 & 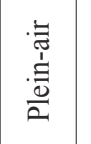 & 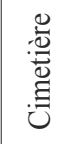 & 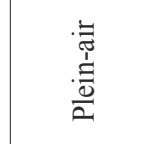 & 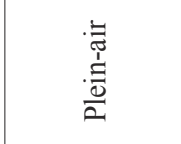 \\
\hline 嶽 & 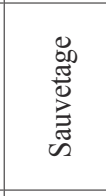 & 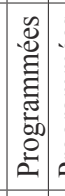 & 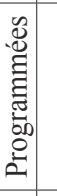 & 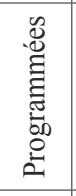 & 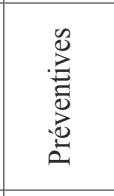 & 总 & 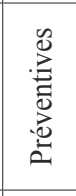 & 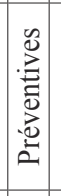 & 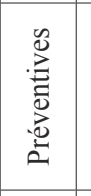 & 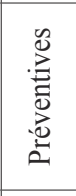 & 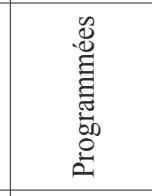 & 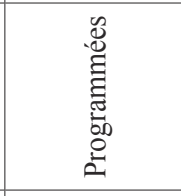 \\
\hline 竞 & $\begin{array}{l}\stackrel{\tilde{N}}{ } \\
\tilde{\omega} \\
\hat{n}\end{array}$ & 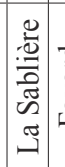 & 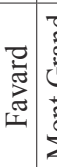 & 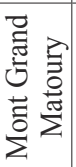 & 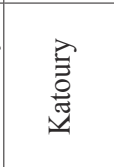 & $\underset{\widetilde{J}}{\tilde{w}}$ & U. & 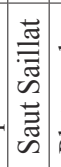 & 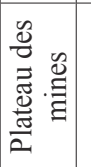 & $\sum_{\dot{z}}^{F}$ & 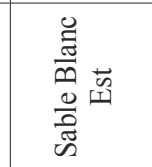 & 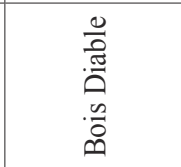 \\
\hline
\end{tabular}


Nouveaux apports sur l'archéologie du littoral de Guyane

\begin{tabular}{|c|c|c|c|c|c|c|c|c|}
\hline 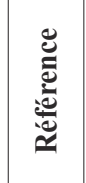 & 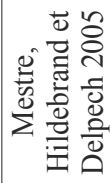 & 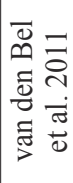 & 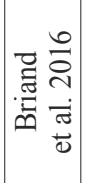 & 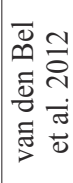 & 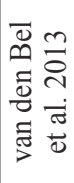 & 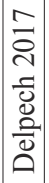 & 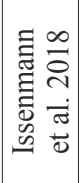 & 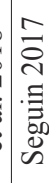 \\
\hline 竧 & $r$ & $\stackrel{\sim}{\sim}$ & $a$ & $r$ & $\because$ & $=$ & - & $N$ \\
\hline : & $\bar{\infty}$ & $\underset{⿱}{\stackrel{\nabla}{\sim}}$ & $\underset{\sim}{\approx}$ & $\overrightarrow{\mathbb{N}}$ & $\overline{\vec{N}}$ & $=$ & $\begin{array}{l}\text { Dे } \\
\text { त }\end{array}$ & $\sim$ \\
\hline 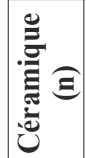 & $\begin{array}{l}8 \\
i n \\
i n\end{array}$ & $\begin{array}{l}\vec{n} \\
m \\
m\end{array}$ & $\begin{array}{l}\sqrt[8]{8} \\
0\end{array}$ & $\begin{array}{l}\stackrel{D}{\sim} \\
\stackrel{+}{+}\end{array}$ & $\begin{array}{l}\hat{a} \\
\text { nิ }\end{array}$ & $\begin{array}{l}\hat{b} \\
\infty \\
\sigma\end{array}$ & $\begin{array}{l}\infty \\
i n \\
\sim\end{array}$ & $\frac{n}{6}$ \\
\hline 总 & 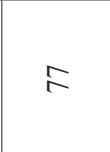 & กี & $\hat{n}$ & $\stackrel{\infty}{n}$ & હે & $m$ & $\widehat{\curvearrowright}$ & in \\
\hline$\tilde{\Xi}$ & 文 & $\begin{array}{l}\stackrel{\infty}{0} \\
i n\end{array}$ & 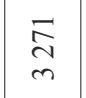 & 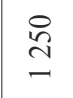 & $\begin{array}{l}3 \\
i \\
n\end{array}$ & $\stackrel{n}{\beth}$ & $\begin{array}{l}8 \\
\infty \\
m\end{array}$ & \& \\
\hline 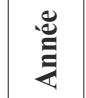 & 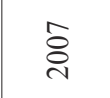 & $\stackrel{\infty}{\stackrel{\infty}{\circ}}$ & \&े & $\stackrel{\circ}{\stackrel{\circ}{\circ}}$ & $\stackrel{\circ}{\stackrel{\circ}{\circ}}$ & $\stackrel{n}{\tilde{c}}$ & $\stackrel{n}{\stackrel{n}{2}}$ & $\stackrel{n}{\stackrel{\sim}{2}}$ \\
\hline 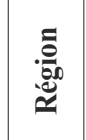 & 离 & 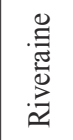 & 离 & 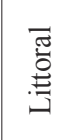 & 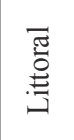 & 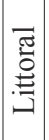 & 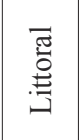 & 莺 \\
\hline 芯 & 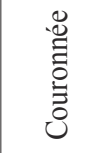 & 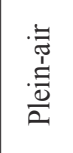 & 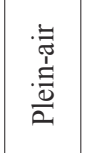 & 寻 & 寻 & 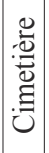 & 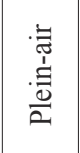 & 岂 \\
\hline 总 & 总 & 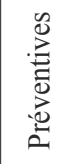 & 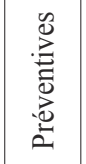 & 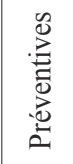 & 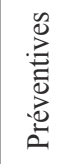 & 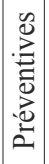 & $\begin{array}{l}\underbrace{0}_{0} \\
.0 \\
0 \\
0 \\
0 \\
0 \\
0\end{array}$ & 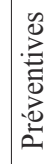 \\
\hline 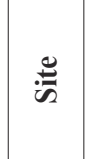 & $\underset{\sim}{\stackrel{\Xi}{\sigma}}$ & 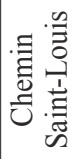 & 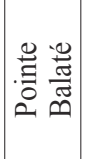 & $\begin{array}{l}\bar{y} \\
\frac{1}{a}\end{array}$ & 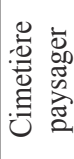 & 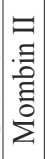 & 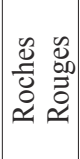 & 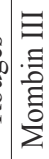 \\
\hline
\end{tabular}


Martijn M. vAN DEN BEL

Annexe II - Répartition chronologique des sites archéologiques au Suriname et en Guyane française par nom et par complexe céramique

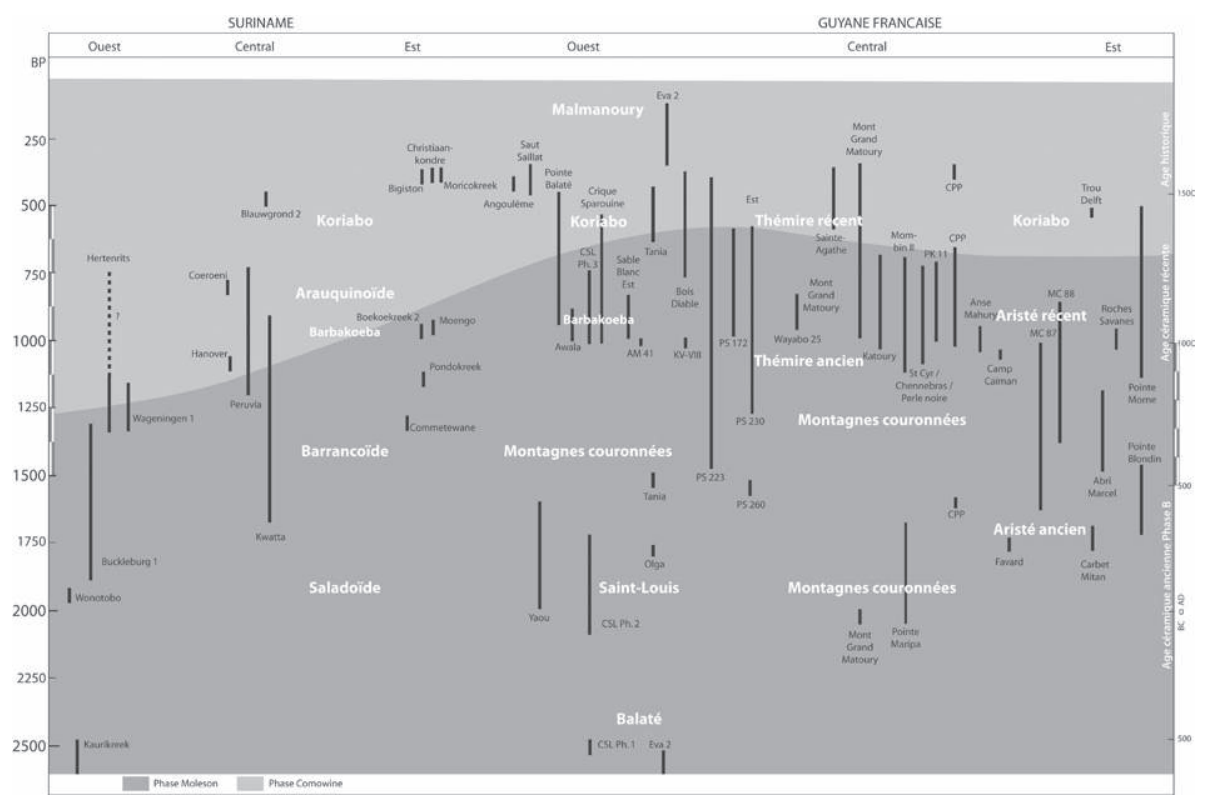

Données issues d'un travail collectif INRAP DOM, SRA Guyane et Versteeg 1980. 